\title{
A Macro-element Based Practical Model for Seismic Analysis of Steel-Concrete Composite High-Rise Buildings
}

\author{
Xiangming Zhou ${ }^{* 1}$ and Guoqiang $\mathrm{Li}^{2}$ \\ ${ }^{1}$ Senior Lecturer in Civil Engineering Design, School of Engineering and Design, Brunel \\ University, Uxbridge, Middlesex UB8 3PH, United Kingdom Tel: +44 1895266 670; Fax: \\ +44 1895269 782; Email: Xiangming.Zhou@brunel.ac.uk \\ ${ }^{2}$ Professor in Structural Engineering, College of Civil Engineering, Tongji University, 1239 \\ Siping Road, Shanghai, 200092, China Tel: +86 216598 2975; Fax: +86 216598 3313; \\ Email: gqli@tongji.edu.cn \\ * Corresponding author
}

Abstract: Seismic behaviour of steel-concrete composite high-rise buildings, composed of external steel frames (SF) and internal concrete tube (CT), with rectangular plan is investigated in this paper. A macro-element based model is established for seismic analysis of composite high-rise buildings aiming at predicting their global responses under earthquakes. By employing this macro-element based model, natural frequencies and vibration modes, storey and inter-storey drifts, overturning moments and storey shear forces of composite structures, induced by earthquakes, are able to be obtained with much less computation time and cost compared with using micro-element based analytical models. To validate its efficiency and reliability, the macro-element based model is employed to analyse a 1/20 scaled-down model of a 25-story steel-concrete composite high-rise building subjected to simulated earthquakes with various intensities through a shaking table. Natural frequencies and storey drifts of the model structure are obtained from numerical analyses and compared with those from shaking table test results. It has been found that the calculated dynamic 
responses of the composite model structure subjected to minor, basic, major and super strong earthquakes agree reasonably well with those obtained from experiments, suggesting that the proposed macro-element based model is appropriate for inelastic time-history analyse for global responses of steel-concrete composite high-rise structures subjected to earthquakes with satisfactory precision and reliability. This research thus provides a practical model for elastic and inelastic deformation check of high-rise composite buildings under earthquakes.

Keywords: Steel-concrete composite structure; High-rise building; Hybrid structure; Seismic design; Macro-element; Half-frame model; Multiple-spring wall element; Time-history analysis

\section{Introduction}

Composite structures, composed of external steel frames (SF) and internal concrete tubes (CT), have been widely adopted for high-rise buildings, especially for super-tall buildings, in recent decades in China [1], due to various advantages such as fast construction, strong lateral translational stiffness and relatively low cost by combing together the two construction materials, steel and concrete, and two structural systems, frame and tube. Compared with steel structures, fire-resistant protection cost and welding work in construction site for composite structure can be largely reduced. While compared with concrete structures, composite structures have much less self-weight, leading to less cost for the foundations. Besides, SF can provide large open floor space and great flexibility in the plan configuration for commercial purpose, while CT has large lateral translational stiffness to resist horizontal loads, making steel-concrete composite structure one of the most efficient structural systems for high-rise buildings that is accepted by both architects and engineers [2].

However, little research has been conducted on the seismic behaviour of such type of high-rise composite structures. Apparently, there are remarkable differences in seismic 
behaviour between SF and CT. In a composite high-rise building, although earthquake load is expected to be taken by both SF and CT through composite action, SF normally takes only a small percentage of the horizontal earthquake load when a composite structure is in elastic state, suggesting that the seismic performance of such type of composite structures depends mainly on CT. So a question may be raised as whether such type of composite structures is appropriate in resisting strong earthquakes or not.

In many codes for seismic design, the maximal top and/or inter-storey drifts of high-rise buildings are limited to certain specified values to maintain structure functional under minor earthquakes and to prevent structural collapse under major earthquakes. For instance, the Chinese Code for Seismic Design of Buildings (GB50011-2010) [3] specifies three earthquake design levels based on the exceeding probabilities in a 50-year return period, namely minor earthquake level (or frequent events) with the exceeding probability of $63 \%$ in 50 years, which is equivalent to a return period of 50 years, moderate earthquake level (or basic events) with the exceeding probability of $10 \%$ in 50 years, which is equivalent to a return period of 475 years, and major earthquake level (or rare but probable events) with the exceeding probability of $2-3 \%$ in 50 years, which is equivalent to a return period of 2000 years. Accordingly, three earthquake performance objectives are stipulated in GB500112010, which are ‘operational objective' of no damage under minor earthquakes, 'repairable objective' of repairable damages under moderate earthquakes; and 'life-safety objective' of no-collapse under major earthquakes. However, the Code adopts a two-phase seismic design method, which is 'structural component strength and elastic global deformation check' on the minor earthquake level to meet the 'operational objective' of no damage; and 'inelastic global deformation check (collapse check)' on the major earthquake level to meet the 'life-safety objective' of no collapse. However, it should be noted that no quantitative design or calculation requirements is specified in GB50011-2010. For the purpose of deformation 
check, inter-story drift ratios for buildings under minor and major earthquakes are limited in the Code as the main index for evaluating seismic performance of buildings under minor earthquakes and preventing structural collapse under major earthquakes. Besides, the Chinese Technical Specification for Concrete Structures of Tall Buildings (JGJ 3-2002) limits top drift ratio, i.e., the ratio between maximal top drift and height of a building, for high-rise concrete buildings under minor earthquakes [4]. It is expected that, under major earthquakes, steel-concrete composite buildings are subjected to certain level of structural damage and deterioration. Non-linear time-history analyses are therefore required to obtain their responses. Finite element method, using microscopic elements, is one candidate for such time-history analyses. However, non-linear time-history finite element analysis may introduce great difficulties such as in modelling the complex structures, in modelling nonlinear hysteretic rules of elements and unacceptable long computational time. A practical and efficient analytical approach for predicting the global responses of composite high-rise buildings subjected to earthquakes with acceptable computation cost is still very welcome by engineers to meet the requirements, especially that for collapse check under major and superstrong earthquakes, of codes for seismic design of high-rise buildings.

Various studies [5-10] have revealed that non-linear time-history analyses of complex structural systems might be efficiently carried out by using analytical approaches based on macroscopic models, rather than microscopic, discrete models. Furthermore, Fajfar et al. [8] have concluded that it is reasonable and efficient to employ relatively simple mathematical models and procedures in analysing the responses of structures subjected to strong earthquakes and found that macro-models and simplified methods can yield quite accurate results provided that the input parameters are adequate. Following their ideas, this paper presents a macroscopic model for time-history analysis of composite high-rise buildings subjected to earthquakes in order to obtain their global responses such as storey and inter- 
storey drifts, in which the steel-concrete composite high-rise building is decomposed of two lateral load-resisting sub-structure systems, SF and CT, connected by rigid floor diaphragms to undergo identical horizontal displacement under earthquakes. To further reduce computational time and cost, macroscopic elements are adopted in the model for analysing steel and concrete members of the two sub-structure systems, SF and CT.

\section{Macro-element based analytical model}

\subsection{Decomposition of composite high-rise structures}

It should be noted that this study is limited to investigate the planar behaviour of composite high-rise buildings with symmetrical plan-sections under one-directional earthquakes. Assuming the floors as rigid diaphragms, a composite structure can be regarded as being composed of two lateral load-resisting sub-structure systems, SF and CT, connected by the floor diaphragms. SF usually contains several plain frames parallel to one of the symmetrical axis of the floor plan and these frames work together to withstand horizontal earthquake loads. In this study, CT is assumed to be rectangular in plan and is composed of web wall panels, parallel to the earthquake excitation direction, and flange wall panels, perpendicular to the earthquake excitation direction. The two substructures, SF and CT, are connected by rigid beams with infinite axial stiffness at floor levels to simulate the rigid floor diaphragm effects. All the plain frames, parallel to the earthquake excitation direction, are further lumped into one and the two web wall panels of the rectangular CT are combined into one along the earthquake excitation direction. An approximate approach, proposed by Li and $\mathrm{Li}$ [11], is implemented into the proposed macro-element based analytical model to take into account the global P- $\Delta$ effect of composite high-rise buildings by introducing a structural geometrical stiffness matrix corresponding to drifts at all storeys. The proposed macroelement based analytical model is illustrated in Fig. 1 for elastic and inelastic time-history 
analyses of the SF and CT composite high-rise buildings subjected to one-dimensional earthquakes.

\subsection{Modelling of SF}

According to Chinese seismic code GB50011-2010, non-linear time-history analyses of high-rise buildings subjected to major earthquakes mainly aim at obtaining their global behaviour, such as storey and inter-storey drifts, for the purpose of preventing structural collapse rather than stiffness, stress, deformation and/or damage of individual structural elements. It is therefore not necessary to obtain stiffness and stress of each member in SF during time-history analyses. Thus, a macroscopic analytical model that can predict the global responses of SF under earthquakes is desirable. In this study, the half-frame model, originally proposed by $\mathrm{Li}$ and $\mathrm{Li}$ [11], is adopted to analyse plain $\mathrm{SF}$, which has been validated as being able to satisfactorily predict the global dynamic behaviour of plane SF subjected to earthquakes but with much less computational cost compared with using microscopic discrete elements. According to the half-frame model, a plane frame is transferred to its equivalent half-frame with only one beam and one column elements at each storey. The geometries and sectional properties of the members of a half-frame can be derived based on those of the members in the original full frame following the rules shown below. In addition, a plastic hinge model with bi-linear moment-curvature hysteretic rule, proposed by Li and Shen [11-12], are utilized for describing the change of flexural stiffness of the members in the equivalent half-frame under cyclic loading.

\subsubsection{Transformation of full plain frame to equivalent half-frame}

The initial flexural stiffness of the half-frame column section is

$$
(E I)_{c}=\sum_{i=1}^{n+1}(E I)_{c i}
$$


The length of the half-frame column is

$$
l_{c}=l_{c i}
$$

The shear factor of the half-frame column section is

$$
r_{c}=\frac{\sum_{i=1}^{n+1}(E I)_{c i} r_{c i}}{\sum_{i=1}^{n+1}(E I)_{c i}}
$$

The initial flexural stiffness of the half-frame beam section is

$$
(E I)_{g}=2 \sum_{i=1}^{n}(E I)_{g i}
$$

The length of the half-frame beam is

$$
l_{g}=\frac{\sum_{i=1}^{n}(E I)_{g i}}{2 \sum_{i=1}^{n} \frac{(E I)_{g i}}{l_{g i}}}
$$

The shear factor of the half-frame beam section is

$$
r_{g}=\frac{\sum_{i=1}^{n} \frac{(E I)_{g i}}{l_{g i}} r_{g i}}{\sum_{i=1}^{n} \frac{(E I)_{g i}}{l_{g i}}}
$$

In Eqs. (3) and (6), the shear factors, $r_{c i}$ and $r_{g i}$, of the column and the beam sections are defined by

$$
r=\frac{12 E I \mu}{G A l^{2}}
$$

where in Eq. (7) $E$ and $G$ are the elongation and shear modulus of elasticity, respectively, of steel; $I, A$ and $l$ are the moment of inertia, the cross-section area and the length of the original full frame members, in this case columns or beams; and $\mu$ is the shape factor for shear deformation. The initial yield moment of the half-frame column is 


$$
\left(M_{s}\right)_{c}=\beta \sum_{i=1}^{n+1}\left(M_{s}\right)_{c i}
$$

The ultimate plastic moment of the half-frame column is

$$
\left(M_{p}\right)_{c}=\sum_{i=1}^{n+1}\left(M_{p}\right)_{c i}
$$

The initial yield moment of the half-frame beam is

$$
\left(M_{p}\right)_{g}=2 \sum_{i=1}^{n}\left(M_{s}\right)_{g i}
$$

The ultimate plastic moment of the half-frame beam is

$$
\left(M_{p}\right)_{g}=2 \sum_{i=1}^{n}\left(M_{p}\right)_{g i}
$$

In the above Eqs. (1) to (6) and (8) to (11), the left hand-side items are the geometries and/or sectional properties of members in the equivalent half-frame while the right hand-side items are the corresponding properties of the original full frame members. The $n$ in Eqs. (1) to (6) and (8) to (11) is the number of beams or columns of the full frame at each storey while the subscripts $c$ and $g$ represent column and beam, respectively. In Eq. (8), $\beta$ is a reduction factor for the initial yield moment of the columns, ranging between 0.7 and 0.9 .

\subsubsection{Modified half-frame model with the consideration of axial deformation of column}

The ordinary half-frame model does not take into account axial deformation of frame columns, which may bring unacceptable errors, since the axial deformation caused by the overturning moment induces additional drift which may become significant as building height increases. In this study, an approximate method is implemented into the ordinary halfframe model to take into account axial deformation of frame columns. According to this method, an integrated elastic column is connected to the ordinary half-frame in series (see Fig. 2) [11]. The moment of inertia of the integrated column section at each storey can be obtained by: 


$$
I_{i}=\sum I_{i j}+\alpha_{i} \sum A_{i j} I_{i j}^{2}
$$

where $I_{i j}, A_{i j}$ are the moment of inertia and the cross-section area, respectively, of the $j$ th column at the $i$ th storey of the full plane SF; $l_{i j}$ is the distance from the $j$ th column at the $i$ th storey to the neutral axis of the ith storey of the full plane SF; $\alpha_{i}$ is a reduction factor taking consideration of non-linear distribution of the axial deformation across columns at the same storey. Therefore, the total drift of SF at each floor diaphragm is composed of that of the ordinary half-frame and that of the integrated column. Thus, the lateral translational stiffness of SF can be formulated as:

$$
\left[\mathrm{K}_{\mathrm{f}}\right]=\left(\left[\mathrm{K}_{\mathrm{hf}}\right]^{-1}+\left[\mathrm{K}_{\mathrm{af}}\right]^{-1}\right)^{-1}
$$

where $\left[\mathrm{K}_{\mathrm{hf}}\right]$ is the lateral translational stiffness matrix of the ordinary half-frame and $\left[\mathrm{K}_{\mathrm{af}}\right]$ is that of the integrated column.

\subsection{Modelling of CT}

The CT in high-rise buildings may be perforated by vertical bands of openings which are normally regular along the height of the CT for architectural aesthetics and functional requirement. In this study, the shear walls in CT with openings are replaced by solid ones with the same length and height but reduced thickness, according to the rule of equivalent global behaviour, in this case top drift, when both the perforated and the equivalent solid walls are subjected to inverse triangular lateral loads, representing the seismic effects, based on elastic analyses. When the rectangular CT is subjected to lateral load parallel to one of its principal axes, the two web wall panels, parallel to the load direction, resist the load cooperatively, while the two flange wall panels, perpendicular to the load direction, one of which undertakes vertical tension (upwards) and the other vertical compression (downwards), form a couple to counteract the global overturning moment caused by horizontal load. The 
two web wall panels are then combined into one and moved to the middle of the CT plan section. The rectangular CT is thus transferred to an I-shaped wall (as shown in Fig. 3) with the contributions of both the web and the flange wall panels being taken into account.

Macro wall models attempt to predict the global behaviour of shear walls by means of a simplified idealization and are suitable for efficient use in non-linear time-history analyses of structural walls subjected to cyclic or earthquake loads. So far, various macro wall element models have been proposed and/or employed for inelastic analysis of shear walls [5-10, 1322], among which, multiple-spring wall models are most frequently adopted in various studies. Multiple-spring wall models consist of several linear or non-linear springs, connected by rigid beams at the top and the bottom floor diaphragms, and each spring is aimed at simulating particular, such as axial, rotational or shear, property of the wall. In this study, the transformed I-shaped wall, representing the CT, is analysed using a so-called bending and shear two-spring wall model (as shown in Fig. 4), which was firstly proposed by Vulcano and Bertero [6], comprising of a rotational spring and a shear spring. The rotational spring represents the flexural property of the wall while the shear spring the shear property of the wall.

A stiffness-degradation trilinear hysteretic rule (see Fig. 5) is employed for both the rotational and the shear springs to depict their hysteretic behaviours under cyclic loading. Values of the main control points on the skeleton of the trilinear hysteretic rules, as well as flexural and shear stiffness of the walls at different deformation stages, are calculated as follows. By considering an elastic cantilever wall, with the height, $h$, moment of inertia, $I$, and Young's modulus, $E$, being subjected to a bending moment $M$ at the free end, and assuming that the two-spring wall element undergoes the same free end rotation as the elastic cantilever wall, the initial stiffness of the rotational spring, $K_{\varphi}$, was given by

$$
K_{\varphi}=2(1-c) E I / h
$$


where $c$ is related to the curvature distribution along the storey height and can be chosen as 0.5 (see Fig. 4). After cracking, the bending stiffness of the wall decreases to $\alpha_{\varphi} K_{\varphi}$, where $\alpha_{\varphi}$ is a reduction factor given by

$$
\alpha_{\varphi}=\left(M_{y}-M_{c}\right) /\left(E I_{c}\left(\varphi_{y}-\varphi_{c}\right)\right)
$$

in which, $M_{y}, M_{c}, \varphi_{y}$ and $\varphi_{c}$ are the yield moment, the crack moment, and their corresponding flexural curvatures, respectively, of the shear wall. The crack moment, $M_{c}$, is given by [6]

$$
M_{c}=Z_{e}\left(f_{t}+\sigma_{0}\right)
$$

where $Z_{e}$ is the elastic section modulus of the transformed I-shaped wall, including the contribution of the longitudinal reinforcements scattered in its web; $f_{t}$ is the uniaxial tensile strength of concrete and $\sigma_{0}$ is the average compressive stress over the wall. The yield moment, $M_{y}$, is given by

$$
M_{y}=\left(A_{s} f_{y}+N / 2\right) \cdot L
$$

where, $A_{s}$ and $f_{y}$ are the area and the yield strength of the longitudinal reinforcement in the flange wall at the tension side; $N$ is the axial force acting on the wall; and $L$ is the overall length of the I-shaped wall (see Fig. 3). Vertical loads are normally assumed to be uniformly distributed over the floor plan. Hence $N$ can be determined by the assigned tributary area occupied by the original CT. The yield moment of the wall at the bottom storey may be better given by

$$
M_{y}=\left(A_{s} f_{y}+0.5 A_{w s} f_{w y}+N / 2\right) L_{w}
$$


where $A_{w s}$ and $f_{w y}$ are the area and the yield strength, respectively, of the longitudinal reinforcements in the web of the I-shaped wall and $L_{w}$ is the length of the web wall (see Fig. 3). The crack curvature, $\varphi_{c}$, of the wall is calculated as:

$$
\varphi_{c}=M_{c} / E I
$$

By taking the first yielding of the reinforcement steel in the flange wall at the tension side as the yielding of the CT section in flexure and assuming that the plain section of the I-shaped wall remains plain during deformation and neglecting the effects of axial force on the curvature of the wall, Vulcano and Bertero [6] derived the yield curvature, $\varphi_{y}^{\prime}$, for the Ishaped shear wall as

$$
\varphi_{y}^{\prime}=\frac{\varepsilon_{s}}{d-k d}
$$

where $\varepsilon_{s}$ is the strain of the reinforcement in the flange wall at the tension side when it yields, $d$ and $k d$ are representative sizes of the wall (see Fig. 6). To take into account the effects of axial force on the wall flexural curvature, Park and Ang [23] suggested a modification to $\varphi_{y}^{\prime}$, and give the yield curvatures, $\varphi_{y}$, as

$$
\varphi_{y}=\left[1+\frac{0.4}{0.84+\rho_{a}} \cdot \frac{\sigma_{0}}{0.3 f_{c}^{\prime}}\right] \cdot \varphi_{y}^{\prime}
$$

where $\rho_{a}=A_{s} f_{y} / A_{w} f_{c}^{\prime}$ in which $A_{w}$ is the cross-sectional area of the wall (see Fig. 3) and $f_{c}^{\prime}=0.8 f_{c u}$ is the cylindrical compressive strength of concrete; and $\sigma_{0}$ is the average compressive stress over the wall. After yielding, the flexural stiffness of the wall is assumed to be $0.5 \%$ of its elastic value to show some strength hardening effects of reinforced concrete walls until reaching the ultimate moment, $M_{u}$, which is given by

$$
M_{u}=\left(A_{s} f_{\max }+N / 2\right) \cdot L
$$


where $f_{\max }$ is the ultimate tensile strength of the longitudinal reinforcement in the flange wall at the tension side.

The initial elastic stiffness of the shear spring, $K_{s}$, is derived as

$$
K_{S}=\frac{G A_{w}}{k h}
$$

where $G$ is the shear modulus of concrete; $k$ is the shape factor for shear deformation; and $h$ is the storey height. The shape factor, $k$, for the typical I-shaped section (see Fig. 3) is given by [13]

$$
k=\frac{3(1+u)\left[1-u^{2}(1-v)\right]}{4\left[1-u^{3}(1-v)\right]}
$$

where $u$ and $v$ are the geometrical parameters of the I-shaped wall (see Fig. 3). After the wall cracks in shear, its shear stiffness decreases to $\alpha_{S} K_{S}$ and $\alpha_{S}$ is given by [5]

$$
\alpha_{s}=0.14+0.46 \frac{\rho_{w h} f_{w y}}{f_{c}^{\prime}}
$$

where $\rho_{w h}$ is the horizontal reinforcement ratio of the wall, $f_{w y}$ is the yield strength of the horizontal reinforcement and $f_{c}^{\prime}=0.8 f_{c u}$ is the cylindrical compressive strength of concrete. The shear stiffness of the wall after yielding in shear is taken as 0.5 percent of its elastic value. The crack shear strength, $V_{c}$, of the wall is taken as [5]

$$
V_{c}=0.438 \sqrt{f_{c}^{\prime}} A_{w}
$$

where $f_{c}^{\prime}=0.8 f_{c u}$ in MPa. The ultimate shear resisting capacity, $V_{u}$, of the wall is evaluated by Hirosawa’s empirical equation as [5]

$$
V_{u}=\left[\frac{0.0679 \rho_{t}^{0.23}\left(f_{c}^{\prime}+17.6\right)}{\sqrt{M / V L+0.12}}+0.845 \sqrt{f_{w y} \rho_{w h}}+0.1 \sigma_{0}\right] b_{e} j
$$


in which $\rho_{t}$ is the effective tensile reinforcement ratio in percentage, $\rho_{t}=\frac{100 A_{s}}{b_{e}(L-h / 2)}$, and $A_{s}$ is the area of longitudinal reinforcements in the tension-side flange wall and $b_{e}$ is the average width of wall section; $\frac{M}{V L}$ is the shear span-to-depth ratio; $f_{w y}$ is the yield strength of horizontal reinforcement of the wall; $\rho_{w h}$ is the effective horizontal reinforcement ratio of the wall, $\rho_{w h}=\frac{A_{w s}}{b_{e} S}$ and $S$ is the spacing between horizontal reinforcement bars in the wall; $\sigma_{0}$ is the average compression stress over the entire wall section; $j$ equates $\frac{7}{8}\left(L-\frac{a}{2}\right)$ while $L$ and $a$ are geometrical parameters shown in Fig. 3. The shear yield strength, $V_{y}$, is approximately taken as the same value as $V_{u}$. The shear span-to-depth ratio, $\frac{M}{V L}$, can be determined by assuming an inverted triangular earthquake load distributed along the height of the wall and, following this idea, the shear span-to-depth ratio of the $k$ th storey was given by Sun and Jiang [24]

$$
\left(\frac{M}{V L}\right)_{k}=\frac{\sum_{i=1}^{m} h_{n-i+1}+\frac{1}{H} \sum_{i=2}^{m}\left[\left(\sum_{j=i}^{m} h_{n-j+1}\right)\left(H-\sum_{i=1}^{k-1} h_{n-i+1}\right)\right]}{L+\frac{L}{H}\left[\sum_{k=2}^{m}\left(H-\sum_{j=1}^{i-1} h_{n-j+1}\right)\right]}
$$

where $H$ is the total height of the wall; $m$ equates $n-k+1$ and $n$ is the storey number of the wall; and $h_{n-i+1}$ and $h_{n-j+1}$ are the height of Storey $(n-i+1)$ and Storey $(n-j+1)$, respectively.

For a two-spring macro wall element with the applied displacements $\left\{\mu_{e}\right\}=\left[\mu_{m} \square \varphi_{m} \square \mu_{m-1} \square \varphi_{m-1}\right]$ (see Fig. 7), if the wall element stiffness matrix $\left[K_{t}\right]$ is given, the deformation energy of the wall element can be formulated as

$$
\frac{1}{2}\left\{\mu_{e}\right\}^{T}\left[K_{t}\right]\left\{\mu_{e}\right\}=\frac{1}{2}\left\{k_{\varphi}\left(\varphi_{m}-\varphi_{m-1}\right)^{2}+k_{s}\left[\left(\mu_{m}-\mu_{m-1}\right)-(1-c) h \varphi_{m}-\operatorname{ch} \varphi_{m-1}\right]^{2}\right\}
$$


where $k_{\varphi}$ and $k_{s}$ are the flexural and shear stiffness of the macro wall element, respectively. By taking partial derivatives of the element deformation energy, i.e., Eq. (29), with respect to the deformation vector, $\left\{\mu_{\mathrm{e}}\right\}$, the two-spring wall element stiffness matrix can be derived as

$$
\left[K_{t}\right]=\left[\begin{array}{cccc}
k_{s} & -k_{s}(1-c) h & -k_{s} & -k_{s} c h \\
& k_{\varphi}+k_{s}(1-c)^{2} h^{2} & k_{s}(1-c) h & -k_{\varphi}+k_{s} c(1-c) h^{2} \\
& & k_{s} & k_{s} c h \\
& & & k_{\varphi}+k_{s} c^{2} h^{2}
\end{array}\right]
$$

\subsection{P-delta effect of high-rise composite structure}

The P- $\Delta$ effect is closely related to vertical loads acting on a structure. For a vertical structural member such as frame column or shear wall, its axial force is contributed by two actions, one caused by overturning moment due to horizontal loads, and the other by vertical loads. Overturning moment induces internal axial force in vertical structural members, increasing in some members but decreasing in others, resulting in a zero net axial force at each storey. Through introducing a geometrical stiffness matrix corresponding to lateral deflections at all storeys, $\mathrm{Li}$ and $\mathrm{Li}$ [11] established an approximate approach to take into account the global P- $\Delta$ effect of high-rise buildings, which is very convenient to be included in a macro-element based analytical model. According to this approach, the structural geometric stiffness matrix, $\left[K_{g}\right]$, caused by the P- $\Delta$ effect, of a high-rise building is given by

$$
\left[K_{g}\right]=\left[\begin{array}{ccccc}
N_{n} & -N_{n} & & & \\
-N_{n} & N_{n}+N_{n-1} & -N_{n-1} & & \\
& -N_{n-1} & & & \\
& & & & -N_{2} \\
& & & -N_{2} & N_{2}+N_{1}
\end{array}\right]
$$


where $N_{i}$, the ratio between the sum of all vertical loads above the ith storey and the height of the ith storey, is given by $N_{i}=\frac{\sum_{j=i}^{n} G_{i}}{h_{i}} ; G_{i}$ is the total vertical load applied on the ith storey; $h_{i}$ is the height of the $i$ th storey and $n$ is the total number of storeys of the building.

\subsection{Lateral translational stiffness of composite structure}

The global lateral translational stiffness, $\left[K_{S}\right]$, of the composite structure (as shown on Fig. 1) is contributed by three parts, the lateral translational stiffness of SF, $\left[K_{F}\right]$, the lateral translational stiffness of CT, $\left[K_{T}\right]$, and the global geometric stiffness, $\left[K_{g}\right]$, i.e.,

$$
\left[K_{S}\right]=\left[K_{F}\right]+\left[K_{T}\right]-\left\lfloor K_{g}\right\rfloor
$$

where $\left[K_{F}\right]$ is the sum of lateral translational stiffness of all the plane steel frames, based on the modified half-frame models, parallel to the earthquake excitation direction, and is given by $\left[K_{F}\right]=\sum_{i=1}^{m}\left[K_{f i}\right]$ where $m$ is the number of steel half-frames along the earthquake excitation direction.

\section{Non-linear time-history analysis and numerical validation}

\subsection{Non-linear time-history analysis}

A routine incremental time-history analysis method is employed. The incremental equations of dynamic equilibrium for a multi-degree of freedom system are

$$
[M]\{\ddot{\Delta x}\}+[C]\{\dot{\Delta x}\}+[K]\{\Delta x\}=-[M][I]\left\{\Delta \ddot{\delta_{g}}\right\}
$$

where $\{\Delta x\},\{\dot{\Delta x}\},\{\ddot{\Delta x}\}$ are the increments of the displacement, velocity and acceleration vectors, respectively, during the time step $\Delta t ;[M],[C]$ and $[K]$ are the mass, damping 
and lateral translation stiffness matrices, respectively; while $\left\{\Delta \ddot{\delta_{g}}\right\}$ is the incremental earthquake acceleration. The non-zero terms of the lumped mass matrix, [M ], are associated only with the translational degree of freedom and remains constant during analyses. The damping matrix is assumed to be proportional to the mass matrix, $[M]$, and the stiffness matrix, $[K]$, according to Rayleigh damping assumption, having the form

$$
[C]=\alpha[M]+\beta[K]
$$

where $\alpha$ and $\beta$ are coefficients which can be determined by selecting suitable damping ratios for two vibration modes. The non-linear dynamic responses of composite high-rise structures, subjected to earthquakes, are able to be obtained through solving Eq. 33 by the Wilson- $\theta$ method, as can be found in many structural dynamics textbooks.

\subsection{Numerical validation}

Two computer codes, SEMFRM and SHEARWALL, were developed for plain steel frames and I-shaped wall structures, respectively. SEMFRM was coded based on the modified half-frame model for elastic and inelastic time-history analyse of steel frame structures subjected to earthquakes while SHEARWALL based on the bending and shear two-spring wall model for elastic and inelastic time-history analyses of shear walls subjected to earthquakes. The two codes were complied in a similar way with the only differences occurring at the element stiffness and the hysteretic rules. The time-history analysis code, based on macro element models proposed in this study, for steel-concrete composite high-rise structures is a simple combination of SEMFRM and SHEARWALL. The ability and reliability of SEMFRM and SHEARWALL for predicting the dynamic response of plain steel frames and shear walls, subjected to earthquakes, were assessed separately, by comparing results with those given by DRAIN-2DX and/or other published results. DRAIN-2DX is a 
general purpose computer program for static and dynamic analysis of plane structures released by Pacific Earthquake Engineering Research Center, UC Berkeley [25]. It performs nonlinear static and dynamic analyses including time-history seismic analyses.

Example 1: A three-bay, 18-storey rigidly-connected steel frame (see Fig. 8) has beams and columns with dimensions and material properties shown in Table 1. A damping ratio of 3\% was adopted for the first two vibration modes for the steel frame in the numerical analyses through SEMFRM and DRAIN-2D. The frequencies of the first 18 vibration modes of the steel frame, calculated by SEMFRM and DRAIN-2D, are presented in Table 2. It can be seen that the frequencies calculated by the two codes are very close indicating that the modified half-frame model and the SEMFRM code are accurate for elastic analyses of steel frames. The maximal storey and inter-storey drifts of the frame, subjected to the $1940 \mathrm{El}$ Centro N-S wave (with the peak ground acceleration scaled to $4.00 \mathrm{~m} / \mathrm{s}^{2}$ and the frame deforms plastically), obtained from SEMFRM and DRAIN-2D are shown in Figs. 9a and b, respectively. The top drift time-history obtained from both codes is presented in Fig. 9c while the roof acceleration time-history calculated from both codes is shown in Fig. 9d. It can be found that good agreement exists between results given by SEMFRM and those by DRAIN2D, indicating that the modified half-frame model and the SEMFRM code are appropriate for non-linear time-history analyses of SF subjected to earthquakes.

Example 2: A 7-storey reinforced concrete wall with an I-shaped cross section is shown in Fig. 10. The web wall is $200 \mathrm{~mm}$ thick and $5400 \mathrm{~mm}$ long. The first storey is $4.5 \mathrm{~m}$ in height and other storeys are all $3.6 \mathrm{~m}$ in height. The two flange walls are $300 \mathrm{~mm} \times 300 \mathrm{~mm}$ in cross-section from the bottom to the top. The mass of the first storey is $6.0 \times 10^{4} \mathrm{~kg}$ while this value becomes $4.8 \times 10^{4} \mathrm{~kg}$ at other storeys. The reinforcement ratio of the web wall is $1.0 \%$ and those of the flange walls are both $3.0 \%$. The concrete has a strength of $f_{c u}=25.67$ MPa, elasticity modulus of $E_{c}=2.814 \times 10^{4} \mathrm{MPa}$ and shear modulus of $G_{C}=1.182 \times 10^{4} \mathrm{MPa}$. 
The reinforcement steel has the yield strength of $210 \mathrm{MPa}$, ultimate strength of $360 \mathrm{MPa}$ and Young's modulus of $210 \mathrm{GPa}$. The structure is subjected to the 1940 El Centro N-S seismic wave with the peak ground acceleration scaled to $0.55 \mathrm{~m} / \mathrm{s}^{2}$ and the shear wall remains elastic. The frequencies of the first 7 vibration modes of the 7-storey reinforced concrete wall, calculated by SHEARWALL and DRAIN-2D, are presented in Table 3 which suggests that the results from both codes agree very well. It has been found under this seismic excitation level, the reinforced concrete wall remains in elastic state so a damping ratio of $2 \%$ is adopted for the structure when it is analysed by both SHEARWALL and DRAIN-2D. The maximal storey and inter-storey drifts, given by SHEARWALL and DRAIN-2D, are shown in Figs. 11a and b, respectively. The top drift time-history and roof acceleration time-history, obtained from both SHEARWALL and DRAIN-2D, are presented in Fig. 11c and d, respectively. It can be seen that the results, obtained by the two codes, accord well with each other, suggesting that the bending and shear two-spring wall model and SHEARWALL code are good enough for time-history analyses of concrete walls subjected to minor earthquakes when all the wall deforms in elastic state.

Example 3: A 7-storey reinforced concrete wall has a plan section similar to that of the structure investigated in Example 2, with dimensions and mass of each storey given in Table 4. The concrete has a modulus of elasticity of $E_{c}=2.15 \times 10^{4} \mathrm{MPa}$ and a shear modulus of $G_{c}$ $=0.922 \times 10^{4} \mathrm{MPa}$. The reinforcement ratio of the web wall is $1.0 \%$ and those of the flange walls are both 3.0\%. The frequencies of the first 7 vibration modes of this 7 -storey reinforced concrete wall, calculated by SHEARWALL, are presented in Table 5. It can be seen that the fundamental period of the structure is $0.34 \mathrm{~s}$ given by SHEARWALL, compared with $0.31 \mathrm{~s}$ given by Song [20], who utilized the four-spring macro wall model similar to that proposed by Linde and Bachmann [17]. It should be noted that, in analysing this 7-storey wall subjected to earthquakes, Song [20] adopted a damping ratio of $2 \%$ for the first two vibration 
modes. The same damping ratios were adopted in this study when using SHEARWALL analysing the seismic behaviour of the reinforced concrete wall in order to compare the results from both studies. The maximal storey and inter-storey drifts of the 7-storey shear wall, when subjected to the 1940 El Centro N-S seismic wave with the peak acceleration scaled to $4.50 \mathrm{~m} / \mathrm{s}^{2}$, obtained from SHEARWALL and Song [20] are shown in Figs. 12a and b, respectively, while the maximal storey shear force and overturning moment in Figs. 12c and d, respectively. The drift and acceleration time-histories of the roof, calculated by SHEARWALL, are presented in Fig. 12e and f, respectively. Considering that SHEARWALL adopts the bending and shear two-spring wall model and the stiffness degradation tri-linear hysteretic rules for the springs while Song [20] utilized the modified four-spring wall model and the origin-orientated shear hysteretic rule for the springs, the results provided by SHEARWALL is acceptable, suggesting that it is able to predict the global response of shear walls subjected to major earthquakes when the wall deforms in plastic state.

\section{Time-history analyses of a scaled-down high-rise composite model structure}

To verify the effectiveness and reliability of the proposed macro-element based analytical model and the code compiled for time-history analysis of high-rise composite structure under earthquakes, shaking table tests were conducted on a 1/20 scaled-down model of a 25-story steel-concrete composite building. The prototype structure is the Technology Centre Building of the East Shanghai Dockyard, which is a typical steel-concrete composite high-rise office building, composed of external SF and internal CT, (as shown in Figs. 13a and b when the building was under construction), located in Pudong, Shanghai, China, a design seismic Intensity 7 zone according to the Chinese Code for Seismic Design of Buildings (GB500112010) [3]. The prototype building was designed mainly following GB50011-2001 [26] the 
previous version of GB50011-2010, the Chinese Technical Specification for Concrete Structures of Tall Buildings (JGJ 3-2002) [4], the Chinese Technical Specification for Steel Structures for Tall Buildings (JGJ 99-98) [27], and the Shanghai Code for Seismic Design of Buildings (DGJ08-9-2003) [28]. The 1/20 model structure was designed and manufactured by scaling down the geometric and material properties of the prototype building following the general principles of similitude theory [29] and the method for determining similitude coefficients for steel-concrete composite high-rise buildings proposed by Lu et al. [30]. The plan and elevation of the model structure are shown in Figs. 14a and b. The model structure has 25 stories with a rectangular concrete tube located at the centre of its plan with the dimensions of $0.885 \mathrm{~m} \times 0.465 \mathrm{~m}$, covering about $15 \%$ of the plan area of the floor (see Fig. 14a). The height of the model structure is $4.902 \mathrm{~m}$, among which the $1^{\text {st }}$ storey is $0.25 \mathrm{~m}$, the $2^{\text {nd }}$ and $3^{\text {rd }}$ storeys are both $0.235 \mathrm{~m}$ while the $4^{\text {th }}$ to $16^{\text {th }}$ storeys are $0.195 \mathrm{~m}$ each and the $17^{\text {th }}$ to $25^{\text {th }}$ storeys are $0.183 \mathrm{~m}$ each in height (see Fig. 14b). The model structure was amounted on a shaking table and excited with a series of waves with various intensities. Fig. 15a shows the test model after the SF and the CT were fixed on the base beams. At this stage, the floor slabs had not been cast. Fig. 15b shows the fully completed model installed on the shaking table. The results of the shaking table tests of the model structure have been published elsewhere [2]. Applying the proposed analytical approach to the scaled-down 25-storey composite structure model, the natural frequencies and storey drifts caused by earthquakes with various intensities are calculated with much less computational cost compared with FE analysis using microscopic discrete elements.

\subsection{Natural frequencies}

Table 6 lists the measured and calculated frequencies of the first 10 vibration modes of the model structure. It should be noted that the macro-element based model proposed in this 
study is for planar structure so that it can only predict the frequencies and modal shapes of translational vibration modes. Therefore only the frequencies of the $\mathrm{X}$ - and Y-direction vibration modes are able to be calculated using the macro-element based model and these values are listed in Table 6. For the Z-direction and torsional vibration modes, only the measured frequencies are presented in Table 6. It can be seen from Table 6 that the calculated vibration frequencies agreed well with those of the measured ones suggesting that the macroelement based model, as well as the computer code, for elastic analysis of composite structure is accurate and reliable.

\subsection{Storey drifts}

As it is well known, soil condition is one of the important factors affecting earthquake inputs to structures. The prototype building was located on Type-IV site soil, which is defined as soil with thickness of soft layer being more than $80 \mathrm{~m}$ and an average shear wave velocity being not more than $140 \mathrm{~m} / \mathrm{s}$ in GB50011-2010 [3]. By considering the spectral density characteristics of Type-IV site soil, 1940 El Centro wave (E-wave) and 1971 San Fernando wave (S-wave) were selected as seismic inputs in shaking table tests. Additionally, a synthetic seismic wave, which is a 1-D wave suitable for Type-IV site soil, was also chosen from DGJ08-9-2003 as seismic input, making totally 3 seismic records used as earthquake inputs in experiment [2]. All the three seismic records were in the format of time-ground motion acceleration. It should be noted that it is stipulated in GB50011-2010 that at least two actual strong motion records and one simulated ground motion should be used as design inputs for assessing seismic performance of building structures. According to GB50011-2010 and DGJ08-9-2003, frequent, basic and rare events represent three levels of ground motions with the return periods of 50, 475 and 2000 years, respectively. The seismic intensity corresponding to frequent, basic and rare events is less than, equal to and higher than the 
design seismic intensity, respectively. The design seismic intensity for the prototype building is Intensity 7 according to GB50011-2010. For the Shanghai area where the prototype building was located, the corresponding peak ground acceleration (PGA) of frequent, basic and rare events are prescribed as $0.035 \mathrm{~g}, 0.1 \mathrm{~g}$, and $0.22 \mathrm{~g}$, respectively, in DGJ08-9-2003. The PGA of super strong earthquakes for design seismic Intensity 7-zone is equivalent to that of major earthquakes of design seismic Intensity 8-zone with the corresponding PGA of 0.40g as specified in GB50011-2010. The peak accelerations of seismic inputs are then adjusted in time-history analyses according to the similitude coefficient for acceleration for various earthquake levels (see Ref. [2]), which are $0.17 \mathrm{~g}, 0.50 \mathrm{~g}$, and $1.10 \mathrm{~g}$ for frequent, basic and rare events of design seismic Intensity 7 , and $2.00 \mathrm{~g}$ for super strong earthquakes of design seismic Intensity 7 or rare events of design seismic Intensity 8.

In experiment, drifts were directly measured and/or were derived via integration of acceleration directly recorded by relevant accelerometers. It has been found that the directly measured drifts agreed well with those obtained from integration [2]. The measured and calculated maximal top drifts of the model structure, under seismic excitations with different intensities, are listed in Table 7. It can be seen that the displacement responses of the model structure, under minor, major and super strong earthquakes, predicted by the proposed analytical approach employing macro element-based model, accorded well with experimental results. This provides solid verifications on the efficiency and the reliability for obtaining the global dynamic response of high-rise composite structures, subjected to earthquakes, by the proposed macro-element based analytical model for time-history analyses.

\section{Conclusions}

In this study, a macro-element based practical model is proposed for elastic and inelastic time-history analyses of steel-concrete composite high-rise buildings subjected to onedirectional earthquakes. The model is able to predict global behaviour of composite high-rise 
buildings with much less computation cost compared with micro-element based analytical models. The analytical model, as well as the hysteretic rules for individual structural elements, has been described with details. The individual sub-structure models and computing codes for plain steel frames and concrete walls, as well as the combined one for composite high-rise buildings, have been assessed. The following conclusions can be drawn:

1. The macro-element based analytical models for high-rise plain steel frames and shear walls are presented for both element model and hysteretic rules, and coded for time-history analyses independently. Compared with other well-known computation tools and/or published results, these macro-element based models can predict the global responses of SF or CT with reasonable accuracy. These models can then be directly implemented into the time-history analyses of high-rise composite structures composed of external SF and internal CT.

2. The composite structure can be decomposed as a system of SF and CT connected in parallel by rigid beams at floor diaphragms. The axial deformation of the frame columns and the global P- $\Delta$ effect of the composite structure can be readily included into the macroelement based analytical model, which enables the proposed analytical model appropriate for composite structures having different configurations of SF and CT in strength and stiffness and having different heights or storeys. By using the macro-element based analytical model, the global behaviour of composite high-rise buildings, subjected to one-dimensional earthquakes, can be obtained with satisfactory accuracy but with much less computational cost, which provides a very efficient practical tool for practising engineers to check seismic performance of steel-concrete composite high-rise buildings subject to major and super strong earthquakes for collapse check.

\section{Acknowledgement}


The authors gratefully acknowledge the financial support from Ministry of Science and Technology of China through the $12^{\text {th }}$ Five-Year Plan Project under Grant No. 2012BAJ13B02.

\section{Reference}

[1] Li GQ. Studies on seismic behaviour of steel-concrete hybrid structures for tall buildings. In: ASCCS editors. Proceedings of the 8th International Conference on Steel-Concrete Composite and Hybrid Structures. Harbin, China: Harbin Institute of Technology Publishers; 2006, p. 702-13.

[2] Zhou XM, Li GQ. Shaking table model test of a steel-concrete composite high-rise building. J Earthquake Engng 2010;14:601-25.

[3] China Ministry of Construction. Code for Seismic Design of Buildings (GB50011-2010). Beijing, China: China Architecture \& Building Press; 2010.

[4] China Ministry of Construction. Technical Specification for Concrete Structures of Tall Buildings (JGJ 3-2002). Beijing, China: China Architecture \& Building Press; 2002.

[5] Otani S, Kabeyasawa T, Shiohara H, Aoyama H. Analysis of the full scale seven story reinforced concrete test structure. In Earthquake Effects on Reinforced Concrete Structures: U. S. -Japan Research, ACI SP 84-8, Detroit, MI: American Concrete Institute; 1985, p. 203239.

[6] Vulcano A, Bertero VV. Analytical model for predicating the lateral response of RC shear wall: evaluation of their reliability. Earthquake Engineering Research Center Report UCB/EERC-87/19, Univ. of California, Berkeley, CA, 1987.

[7] de al Llera JC, Vasquez J, Chopra AK, Almazan JL. A macro-element model for inelastic building analysis. Earthquake Engng Struct Dyn 2000;29:1725-57. 
[8] Fajfar P, Fischinger M, Dolsek M. Macro-models and simplified methods for efficient structural analysis in earthquake engineering. In: Ibrahimbegovic A, Brank B, editors. Engineering Structures under Extreme Conditions: Multi-physics and Multi-scale Computer Models in Non-linear Analysis and Optimal Design, Book series: NATO Science Series, SubSeries III: Computer and Systems Sciences. Bled, Slovenia; 2005, p. 22-49.

[9] Kim TW, Foutch DA, Lafave J.M. A practical model for seismic analysis of reinforced concrete shear wall buildings. J Earthquake Engng 2005;9:393-417.

[10] Figini R, Paolucci R, Chatzigogos CT. A macro-element model for non-linear soilshallow foundation-structure interaction under seismic loads: theoretical development and experimental validation on large scale tests. Earthquake Engng Struct Dyn 2011;41:475-93.

[11] Li GQ, Li JJ. Advanced analysis and design of steel frames. West Sussex, England: John Wiley \& Sons, Ltd; 2007.

[12] Li GQ, Shen ZY. Elastic and Elasto-Plastic Analysis of Steel Frames. Shanghai, China: Shanghai Science and Technology Press; 1996 (in Chinese).

[13] Kabeyasawa T, Shiohara H, Otani S. U.S.-Japan cooperative research on R/C full-scale building test, Part 5: Discussion of dynamic response system. Proceedings of the $8^{\text {th }}$ World Conference on Earthquake Engineering, San Francisco, CA; 1984.

[14] Vulcano A, Bertero VV, Colotti V. Analytical model of R/C structural walls. Proceedings of the $9^{\text {th }}$ World Conference on Earthquake Engineering, Tokyo-Kyoto, Japan; 1988.

[15] Fajfar P, Fischinger M. Mathematical modeling of reinforced concrete structural walls for nonlinear seismic analysis. Proceedings of the $1^{\text {st }}$ European Conference on Structural Dynamics (EUROPEAN 90), Structural Dynamics, 1990;1-2:471-8.

[16] Colotti, V. Shear behavior of RC structural walls. J Struct Engng 1993;119:728-746. 
[17] Linde P, Bachmann H. Dynamic modeling and design of earthquake-resistant walls. Earthquake Engng Struct Dyn;23:1331-50.

[18] Azzato F, Vulcano A. Modeling of RC frame-wall structures for nonlinear seismic analysis. Proceedings of the $11^{\text {th }}$ World Conference on Earthquake Engineering, Acapulco, Mexico, 1996.

[19] Milev JI. Two dimensional analytical model of reinforced concrete shear walls. Proceedings of the $11^{\text {th }}$ World Conference on Earthquake Engineering, Acapulco, Mexico, 1996.

[20] Song YX. Analysis of Seismic Response of Frame-Wall Structures Considering SoilPile-Structure Interaction, PhD Thesis, Tongji University, China; 1998 (in Chinese).

[21] Ghobarah A, Youssef M. Modelling of reinforced concrete structural walls. Engng Struct 1999;21:912-23.

[22] Bao YH, Kunnath SK. Simplified progressive collapse simulation of RC frame-wall structures. Engng Struct 2010;32:3153-62.

[23] Park YJ, Ang AHS. Mechanistic seismic damage model for reinforced concrete. J Struct Engng, ASCE 1985;111:722-39.

[24] Sun JJ, Jiang JR. Stochastic seismic response and reliability analysis of hysteretic frameshear wall structures. Earthquake Engng Engng Vibration 1992;12:59-68 (in Chinese).

[25] Prakash V, Powell G, Campbell S. DRAIN-2DX base program description and user guide - Version 1.10. Report No. UCB/SEMM-93/17 and 93/18, Structural Engineering, Mechanics and Materials, Dept. of Civil Engng., Univ. of California, Berkeley, CA.

[26] China Ministry of Construction. Code for Seismic Design of Buildings (GB50011-2001). Beijing, China: China Architecture \& Building Press; 2001.

[27] China Ministry of Construction. Technical Specification for Steel Structure for Tall Buildings (JGJ 99-98). Beijing, China: China Architecture \& Building Press; 1998. 
[28] Shanghai Government Construction and Management Commission. Code for Seismic Design of Buildings (DGJ08-9-2003). Shanghai Standardization Office, Shanghai, China; 2003.

[29] Harris HG, Sabnis G. Structural modelling and experimental techniques. $2^{\text {nd }}$ ed. Englewood Cliffs, New Jursey: Prentice-Hall; 1989.

[30] Lu XL, Zou Y, Lu WS, Zhao B. Shaking table model test on Shanghai World Financial Center Tower. Earthquake Engng Struct Dyn 2007;36:439-57. 


\section{APPENDIX I TABLES}

Table 1 Geometries and sectional properties of the H-shaped members of the steel frame in Example 1

\begin{tabular}{|c|c|c|c|c|c|c|}
\hline $\begin{array}{c}\text { Member } \\
\text { location }\end{array}$ & $\begin{array}{c}\text { Height } \\
(\mathrm{mm})\end{array}$ & $\begin{array}{c}\text { Width } \\
(\mathrm{mm})\end{array}$ & $\begin{array}{c}\text { Web } \\
\text { thickness } \\
(\mathrm{mm})\end{array}$ & $\begin{array}{c}\text { Flange } \\
\text { thickness } \\
(\mathrm{mm})\end{array}$ & $\begin{array}{c}\text { Initial yield } \\
\text { moment } \\
(\mathrm{KN} . \mathrm{mm})\end{array}$ & $\begin{array}{c}\text { Ultimate yield } \\
\text { moment } \\
(\mathrm{KN} . \mathrm{mm})\end{array}$ \\
\hline $\begin{array}{c}\text { Beams of Storey } \\
\text { 1-6 }\end{array}$ & 900 & 750 & 25 & 35 & $5.7535 \times 106$ & $6.0884 \times 106$ \\
\hline $\begin{array}{c}\text { Beams of Storey } \\
7-12\end{array}$ & 800 & 600 & 24 & 30 & $3.6127 \times 10^{6}$ & $3.8678 \times 10^{6}$ \\
\hline $\begin{array}{c}\text { Beams of Storey } \\
\text { 13-18 }\end{array}$ & 700 & 550 & 16 & 22 & $2.1207 \times 10^{6}$ & $2.2546 \times 10^{6}$ \\
\hline $\begin{array}{c}\text { Edge columns } \\
\text { of Storey 1-6 }\end{array}$ & 650 & 500 & 16 & 20 & $1.6543 \times 10^{6}$ & $1.7700 \times 10^{6}$ \\
\hline $\begin{array}{c}\text { Internal columns } \\
\text { of Storey 1-6 }\end{array}$ & 700 & 550 & 16 & 22 & $2.1207 \times 10^{6}$ & $2.2546 \times 10^{6}$ \\
\hline $\begin{array}{c}\text { Columns of } \\
\text { Storey 7-12 }\end{array}$ & 650 & 500 & 14 & 20 & $1.6269 \times 10^{6}$ & $1.7283 \times 10^{6}$ \\
\hline $\begin{array}{c}\text { Columns of } \\
\text { Storey 13-18 }\end{array}$ & 600 & 500 & 14 & 18 & $1.3583 \times 10^{6}$ & $1.4450 \times 10^{6}$ \\
\hline
\end{tabular}


Table 2 Frequencies of the first 18 vibration modes of the steel frame in Example 1

\begin{tabular}{|c|c|c|}
\hline Order & $\begin{array}{c}\text { By SEMFRM } \\
\text { (Hz) }\end{array}$ & $\begin{array}{c}\text { By DRAIN-2D } \\
\text { (Hz) }\end{array}$ \\
\hline 1 & 0.49 & 0.48 \\
\hline 2 & 1.58 & 1.49 \\
\hline 3 & 2.81 & 2.57 \\
\hline 4 & 3.95 & 3.67 \\
\hline 5 & 5.20 & 4.85 \\
\hline 6 & 6.40 & 6.01 \\
\hline 7 & 7.47 & 7.11 \\
\hline 8 & 8.55 & 8.18 \\
\hline 9 & 9.66 & 9.31 \\
\hline 10 & 10.69 & 10.44 \\
\hline 11 & 11.78 & 11.56 \\
\hline 12 & 12.64 & 12.48 \\
\hline 13 & 13.32 & 13.23 \\
\hline 14 & 14.11 & 14.18 \\
\hline 15 & 14.61 & 14.80 \\
\hline 16 & 15.41 & 15.54 \\
\hline 17 & 15.88 & 16.08 \\
\hline 18 & 16.70 & 16.82 \\
\hline
\end{tabular}


Table 3 Frequencies of the first 7 vibration modes of the 7-storey wall in Example 2

\begin{tabular}{|c|c|c|}
\hline Order & $\begin{array}{c}\text { By SHEARWALL } \\
\text { (Hz) }\end{array}$ & $\begin{array}{c}\text { By DRAIN-2D } \\
\text { (Hz) }\end{array}$ \\
\hline 1 & 2.05 & 1.96 \\
\hline 2 & 10.96 & 10.39 \\
\hline 3 & 25.06 & 24.04 \\
\hline 4 & 39.53 & 36.10 \\
\hline 5 & 53.15 & 50.36 \\
\hline 6 & 64.28 & 57.41 \\
\hline 7 & 71.48 & 65.09 \\
\hline
\end{tabular}


Table 4 Geometries and mass of the 7-storey shear wall in Example 3

\begin{tabular}{|c|c|c|c|c|c|c|c|}
\hline Storey No. & 1 & 2 & 3 & 4 & 5 & 6 & 7 \\
\hline Height (m) & 3.795 & 3.300 & 3.325 & 3.300 & 3.300 & 3.350 & 3.330 \\
\hline Cross-section & $\mathrm{a}=800$ & $\mathrm{a}=800$ & $\mathrm{a}=750$ & $\mathrm{a}=750$ & $\mathrm{a}=750$ & $\mathrm{a}=650$ & $\mathrm{a}=650$ \\
\hline & $\mathrm{b}=800$ & $b=800$ & $b=750$ & $b=750$ & $b=750$ & $b=650$ & $b=650$ \\
\hline $\begin{array}{c}(\mathrm{mm}-\mathrm{mm}- \\
\mathrm{mm})\end{array}$ & $t=200$ & $t=200$ & $\mathrm{t}=180$ & $t=180$ & $\mathrm{t}=180$ & $\mathrm{t}=180$ & $t=180$ \\
\hline Mass (Kg) & $4.8 \times 10^{4}$ & $4.8 \times 10^{4}$ & $4.8 \times 10^{4}$ & $4.8 \times 10^{4}$ & $4.8 \times 10^{4}$ & $4.8 \times 10^{4}$ & $6.07 \times 10^{4}$ \\
\hline
\end{tabular}

Note: a, b and t are geometrical parameters as shown in Fig.10. 
Table 5 Frequencies of the first 7 vibration modes of the 7-storey wall in Example 3

\begin{tabular}{|c|c|}
\hline Order & $\begin{array}{c}\text { By SHEARWALL } \\
\text { (Hz) }\end{array}$ \\
\hline 1 & 2.89 \\
\hline 2 & 13.18 \\
\hline 3 & 27.71 \\
\hline 4 & 41.33 \\
\hline 5 & 53.17 \\
\hline 6 & 61.89 \\
\hline 7 & 66.99 \\
\hline
\end{tabular}


Table 6 Natural frequencies of the first 10 vibration modes of the model structure

\begin{tabular}{|c|c|c|c|}
\hline Order & Measured (Hz) & $\begin{array}{c}\text { Calculated } \\
(\mathbf{H z})\end{array}$ & $\begin{array}{c}\text { Vibrating } \\
\text { direction }\end{array}$ \\
\hline 1 & 4.30 & 4.31 & $\mathrm{X}$ \\
\hline 2 & 5.66 & 5.59 & $\mathrm{Y}$ \\
\hline 3 & 7.62 & - & $\mathrm{Z}$ \\
\hline 4 & 20.12 & 19.82 & $\mathrm{X}$ \\
\hline 5 & 20.70 & - & $\mathrm{Z}$ \\
\hline 6 & 25.39 & 26.94 & $\mathrm{Y}$ \\
\hline 7 & 30.27 & - & $\mathrm{Z}$ \\
\hline 8 & 37.70 & - & $\mathrm{Z}$ \\
\hline 9 & 41.60 & 45.48 & $\mathrm{X}$ \\
\hline 10 & 45.12 & 51.46 & $\mathrm{Y}$ \\
\hline
\end{tabular}


Table 7 Maximal top drifts of the model structure under X-direction earthquakes

\begin{tabular}{|c|c|c|c|}
\hline Seismic case & \multicolumn{3}{|c|}{ Top drift (mm) } \\
\cline { 2 - 4 } & Integrated & Measured & Calculated \\
\hline $\begin{array}{c}\text { Frequent, } \\
\text { Intensity 7 (E) }\end{array}$ & 3.51 & 5.22 & 3.88 \\
\hline $\begin{array}{c}\text { Frequent, } \\
\text { Intensity 7 (S) }\end{array}$ & 6.45 & 7.62 & 6.74 \\
\hline $\begin{array}{c}\text { Basic, } \\
\text { Intensity 7 (E) }\end{array}$ & 10.23 & 12.09 & 14.05 \\
\hline $\begin{array}{c}\text { Basic, } \\
\text { Intensity 7 (S) }\end{array}$ & 9.28 & 10.30 & 12.22 \\
\hline $\begin{array}{c}\text { Rare, Intensity } \\
7 \text { (E) }\end{array}$ & 21.72 & 24.44 & 25.23 \\
\hline $\begin{array}{c}\text { Rare, Intensity } \\
7 \text { (S) }\end{array}$ & 12.34 & 15.16 & 16.10 \\
\hline $\begin{array}{c}\text { Rare, Intensity } \\
\text { 8 (P) }\end{array}$ & 102.29 & 109.19 & 124.40 \\
\hline
\end{tabular}




\section{APPENDIX II FIGURES}

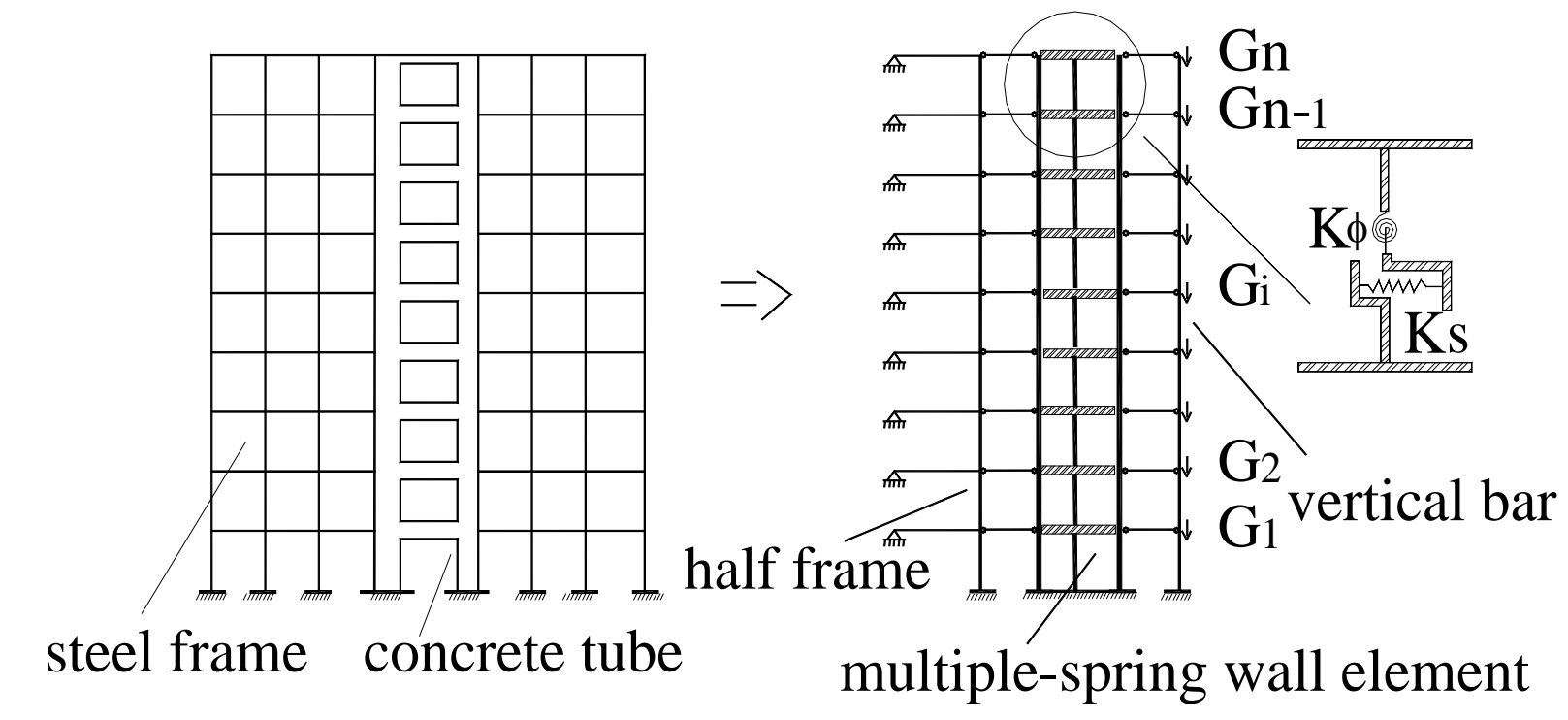

Fig. 1 The proposed analytical model for composite high-rise structures 


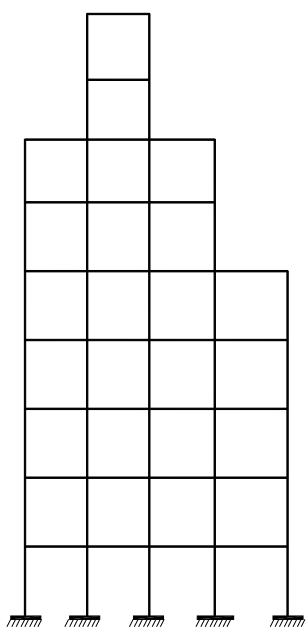

(a)

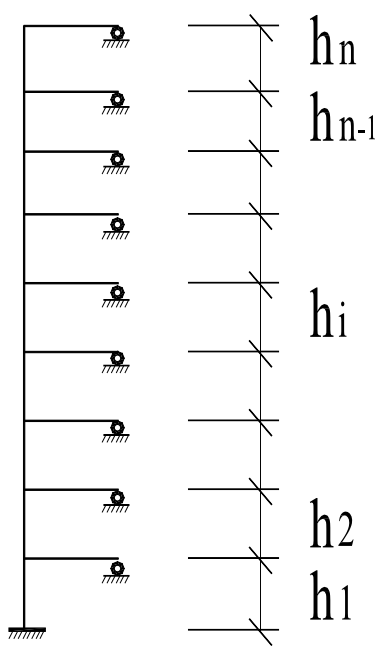

(b)

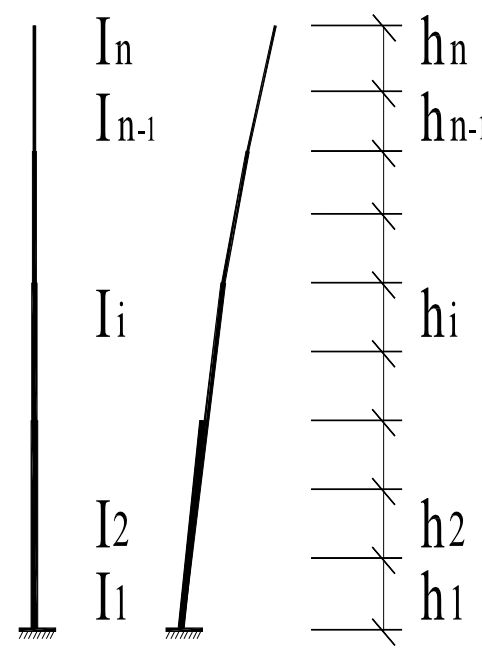

(c)

Fig. 2 Half-frame model with integrated elastic column connected in series: (a) original full frame; (b) equivalent half-frame; (c) integrated elastic column 


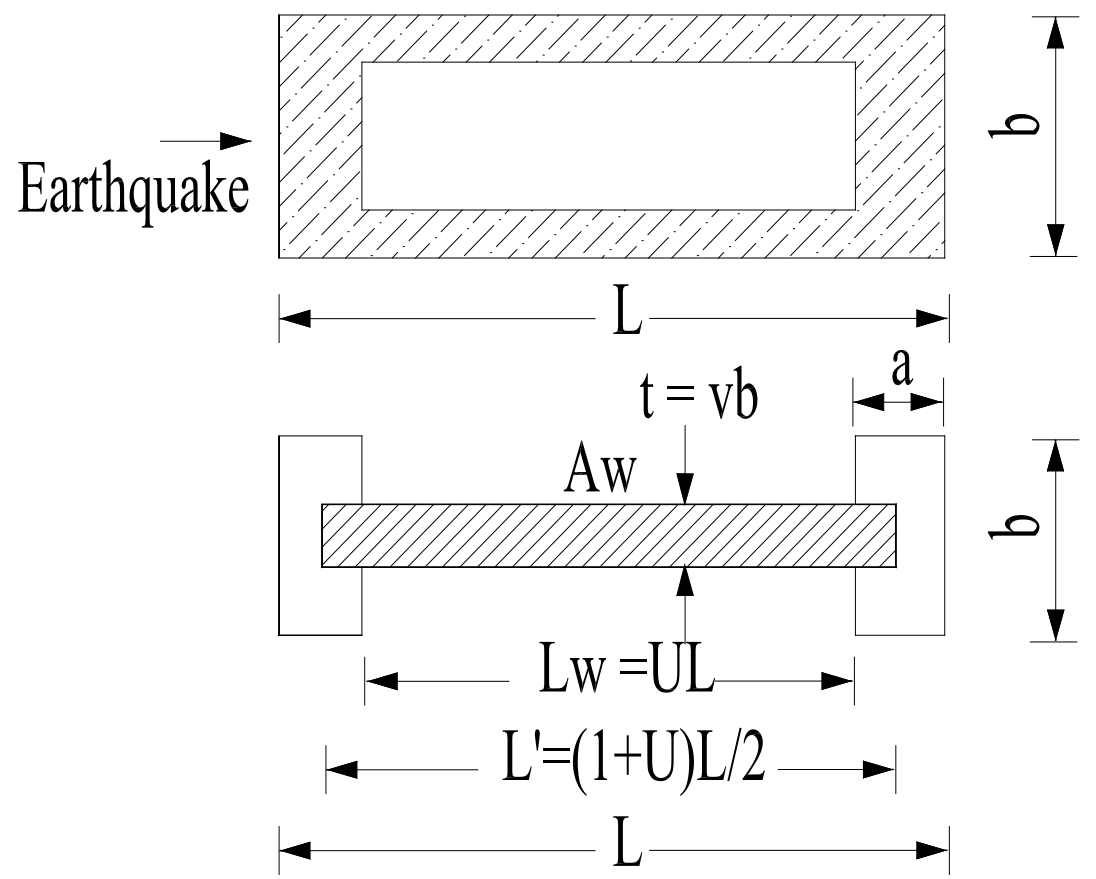

Fig. 3 Concrete tube and its equivalent I-shaped solid wall 


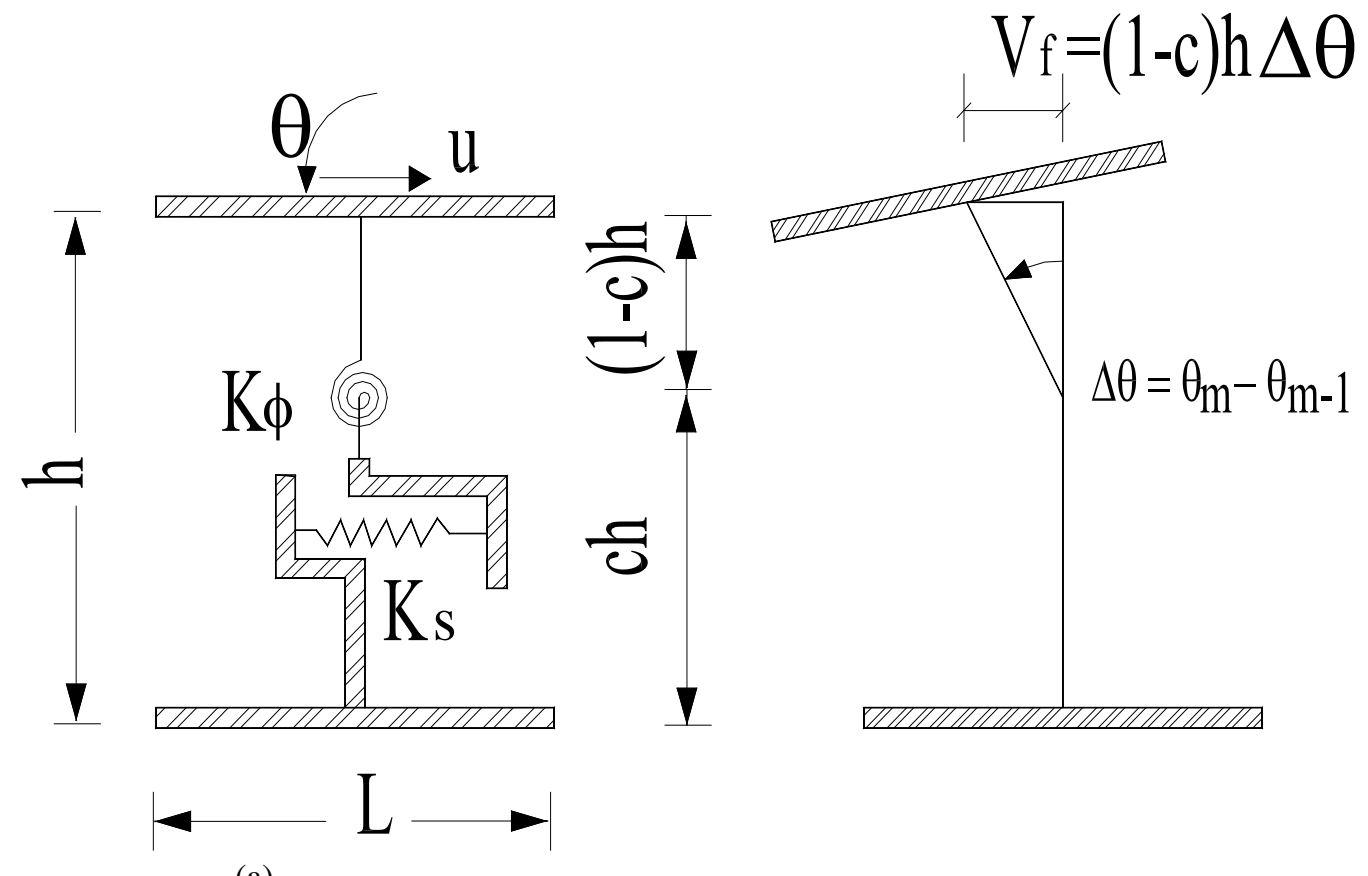

(b)

Fig. 4 The bending and shear two-spring macro wall element 

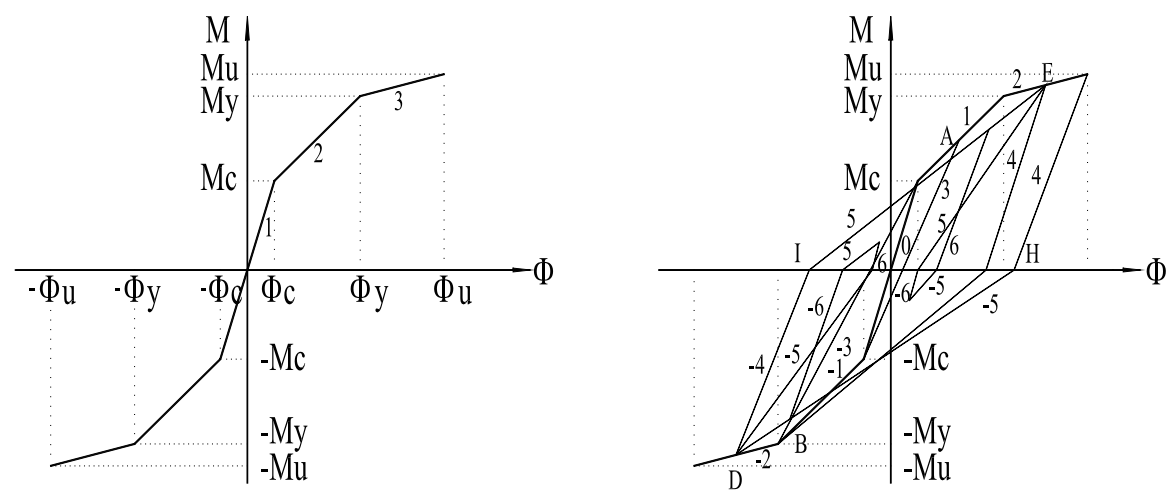

(a)
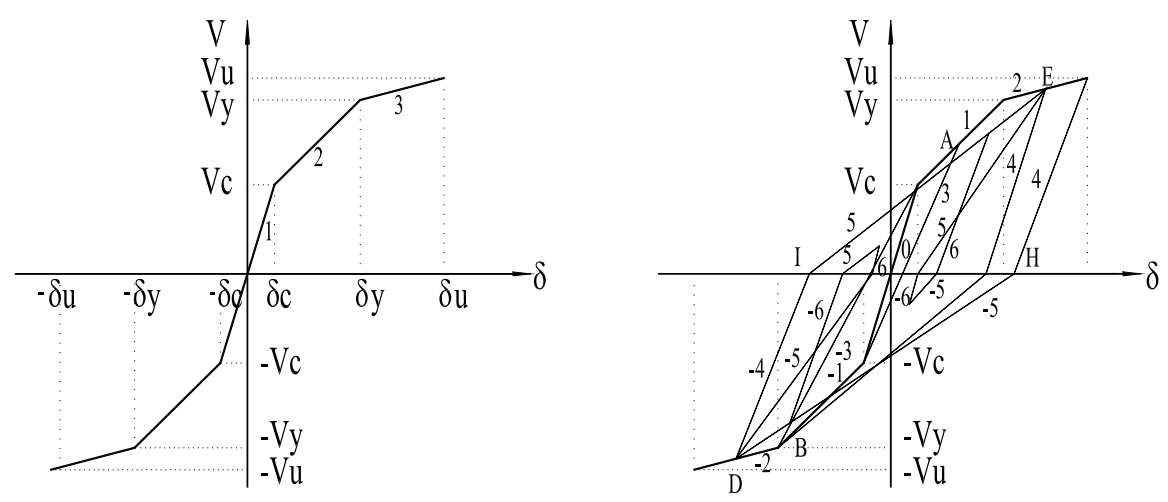

(b)

Fig. 5 Hysteretic rules for rotational spring (a) and shear spring (b) in the two-spring wall element 


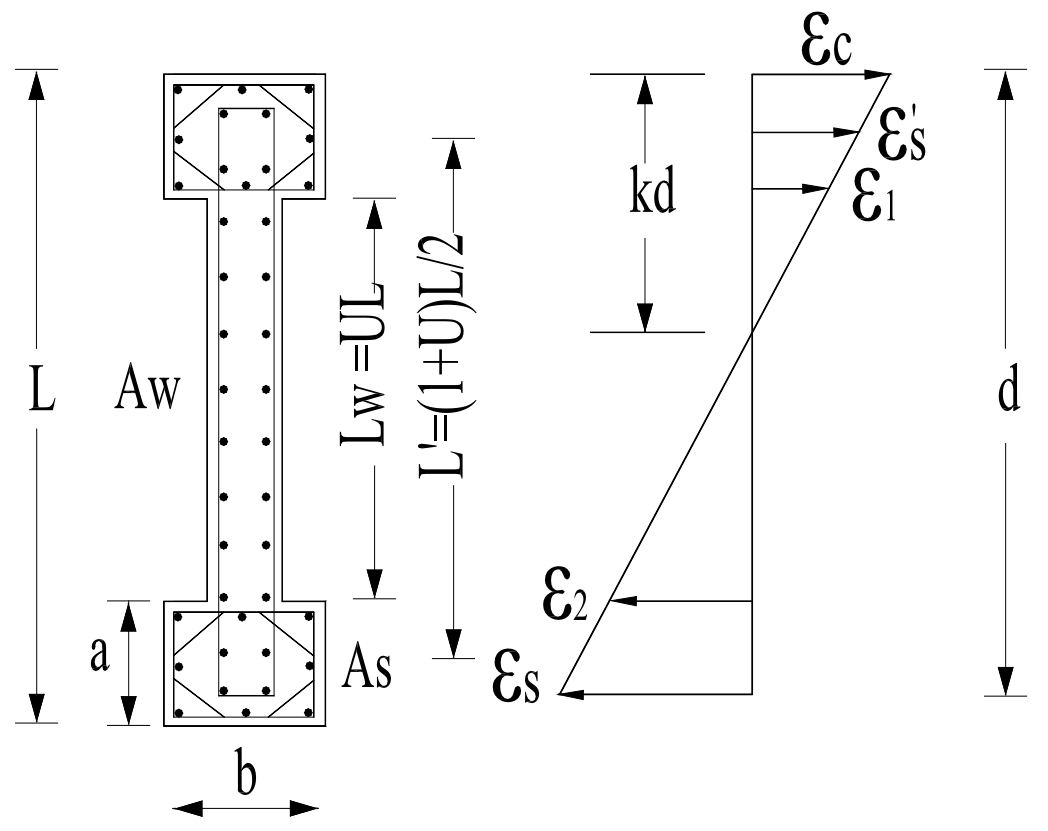

Fig. 6 I-shaped shear wall and strain distribution under bending 


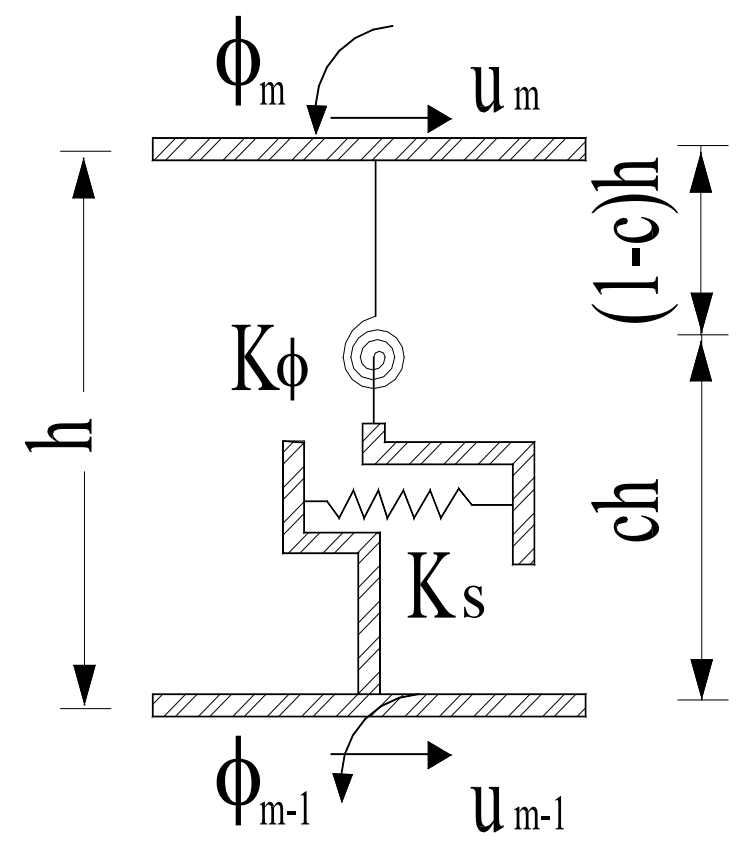

Fig. 7 The two-spring wall element and the applied displacement field 


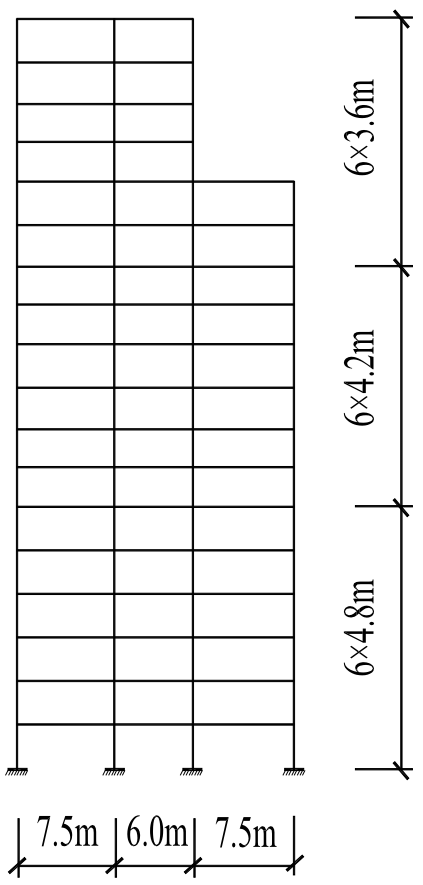

Fig. 8 Elevation of the steel frame in Example 1 


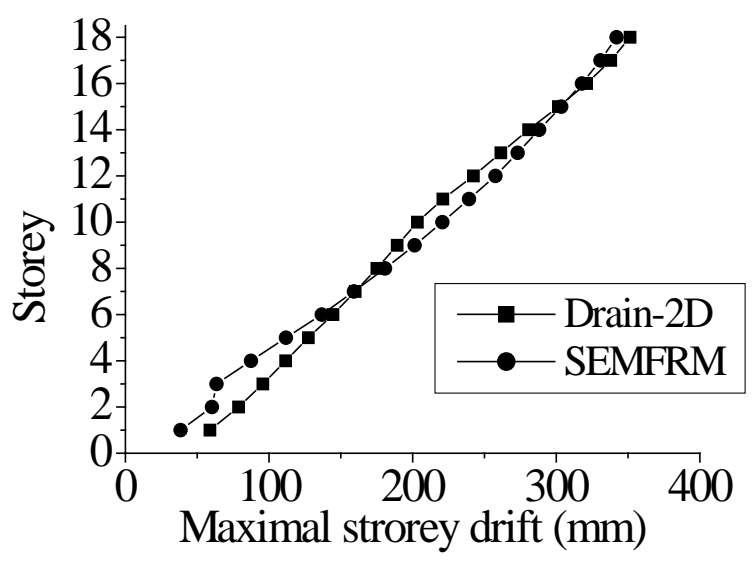

(a)

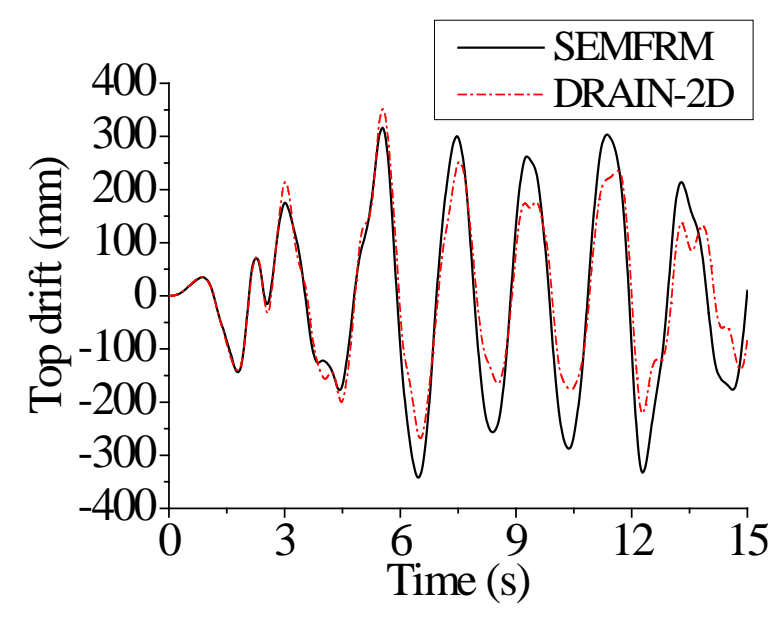

(c)

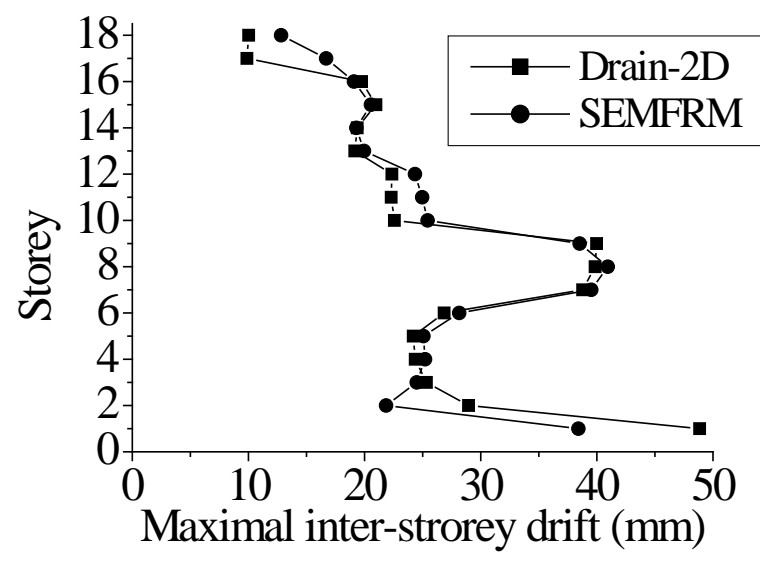

(b)

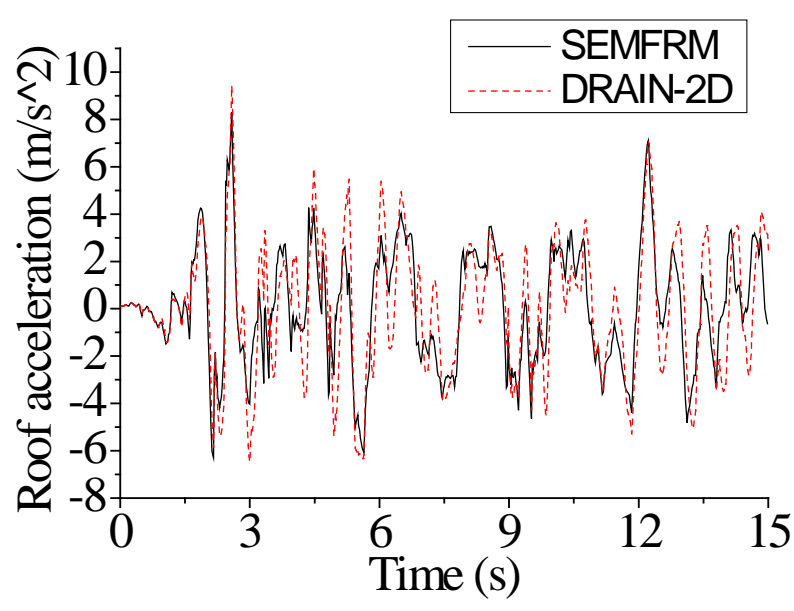

(d)

Fig. 9 Time-history analyse results for Example 1: (a) maximal storey drift; (b) maximal inter-storey drift; (c) top drift time-history; and (d) roof acceleration time-history 


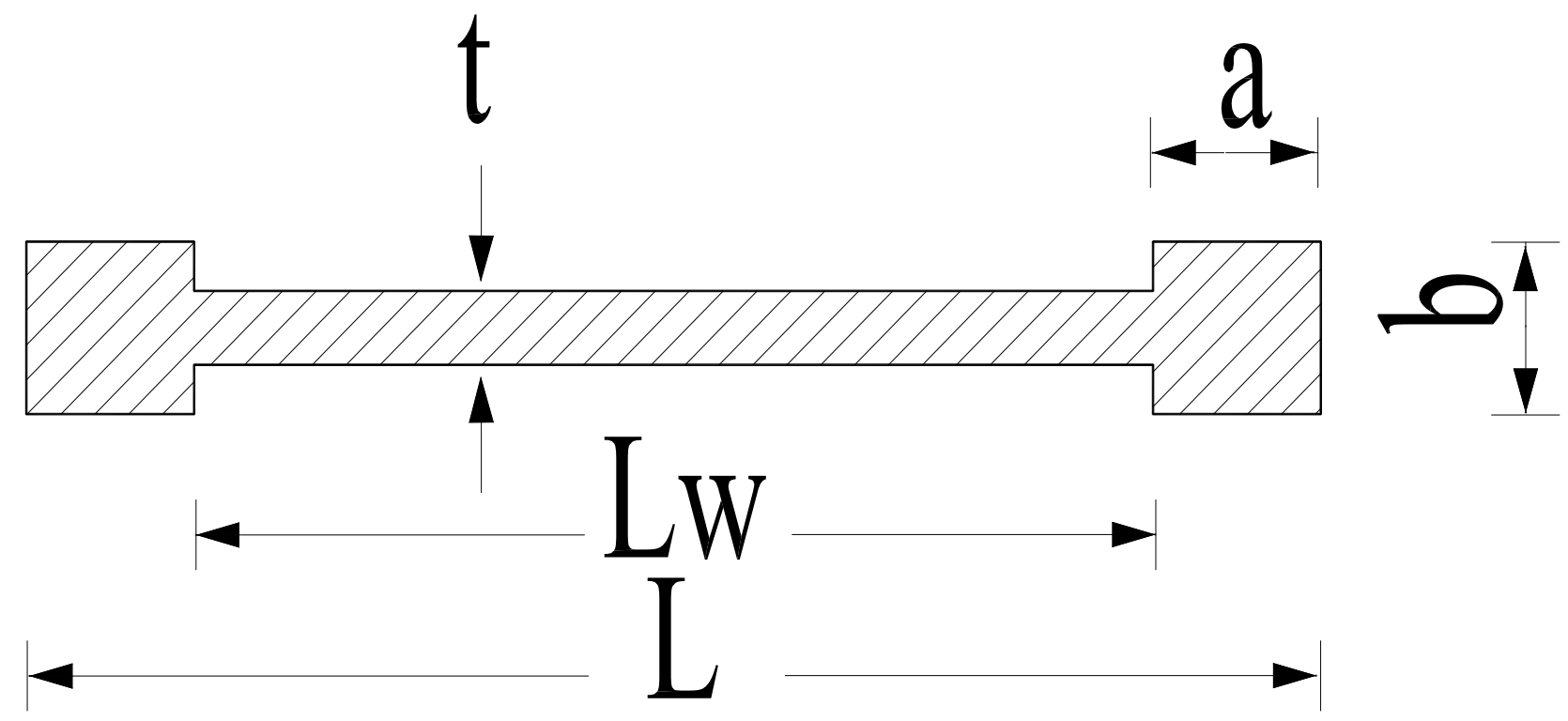

Fig. 10 Cross-section of the 7-storey shear wall in Examples 2 and 3 


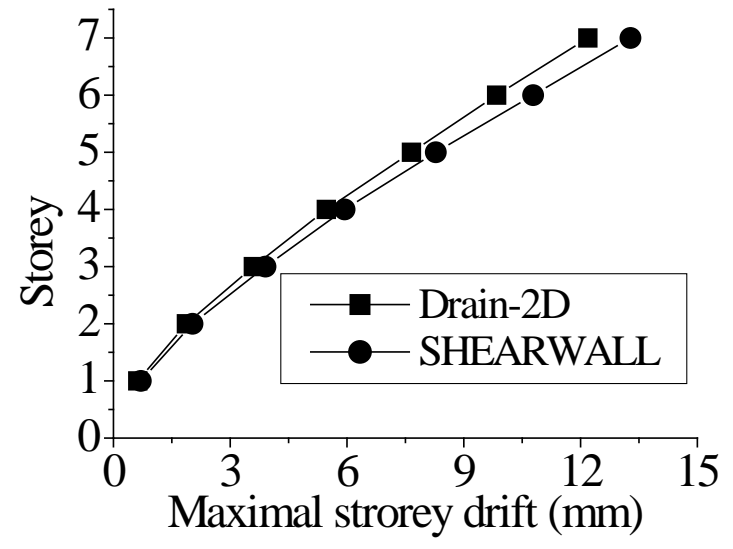

(a)

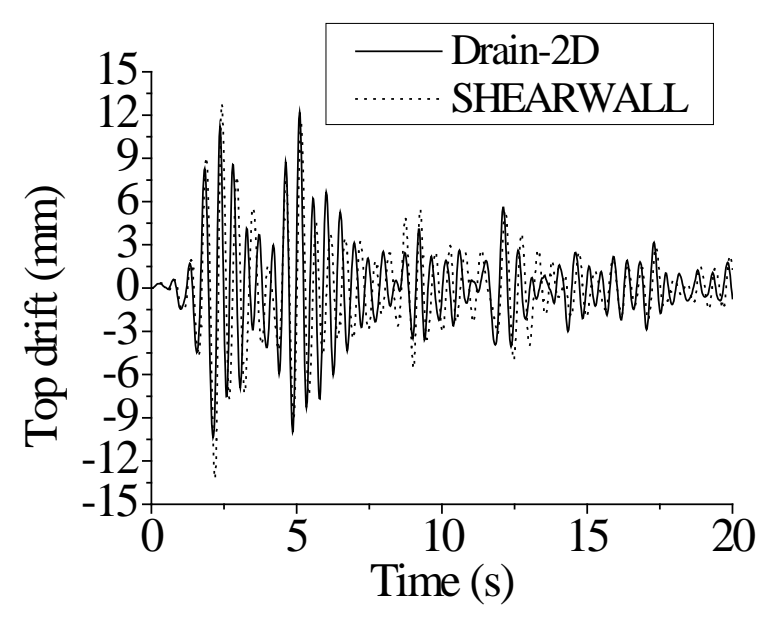

(c)

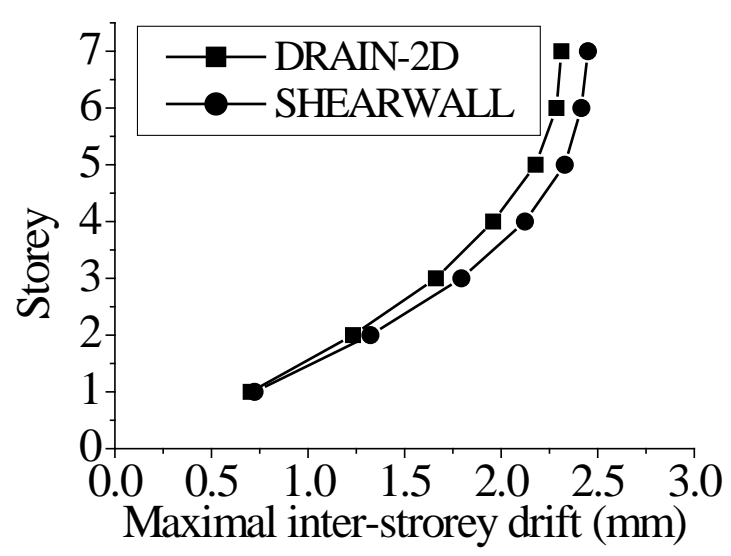

(b)

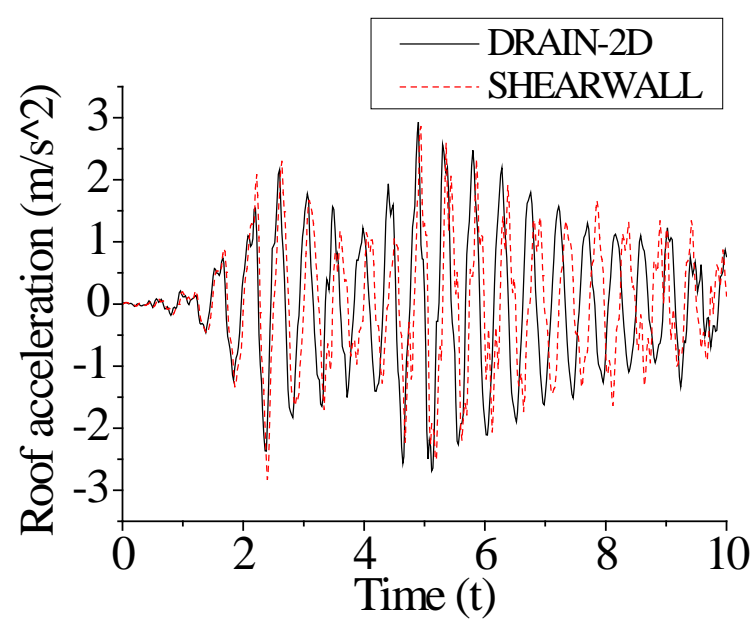

(d)

Fig. 11 Time-history analyse results of Example 2: (a) maximal storey drift; (b) maximal inter-storey drift; (c) top drift time-history; (d) roof acceleration time-history 


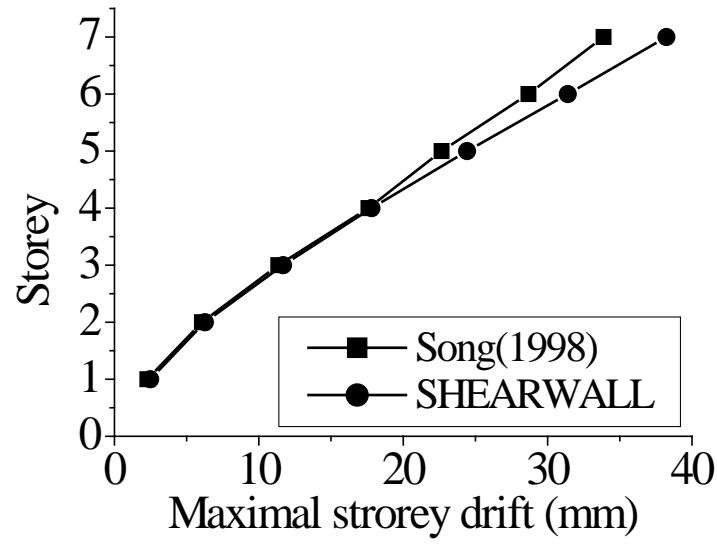

(a)

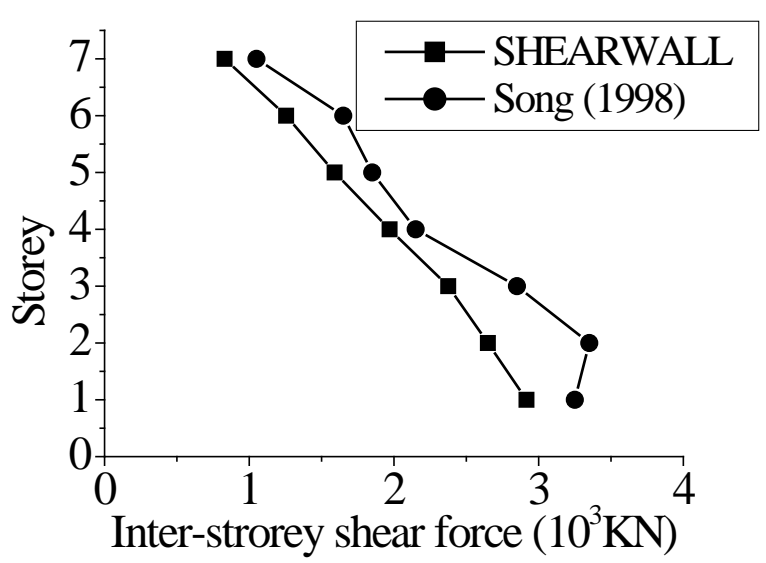

(c)

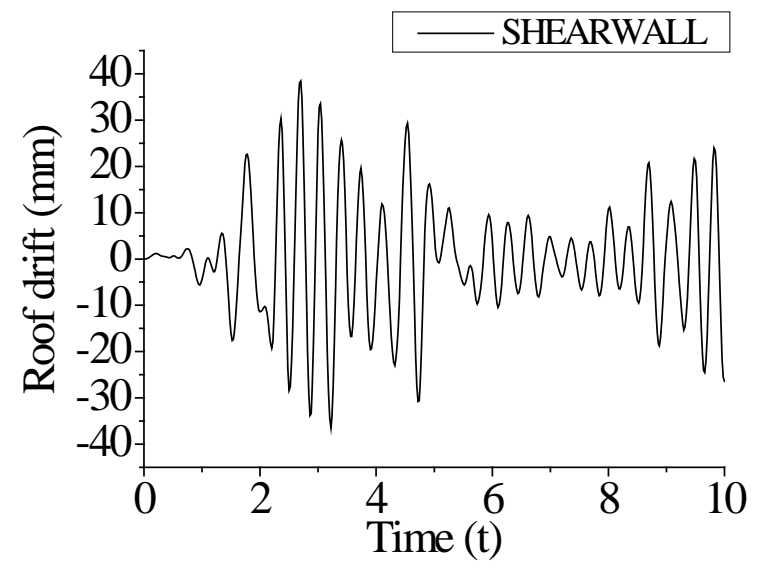

(e)

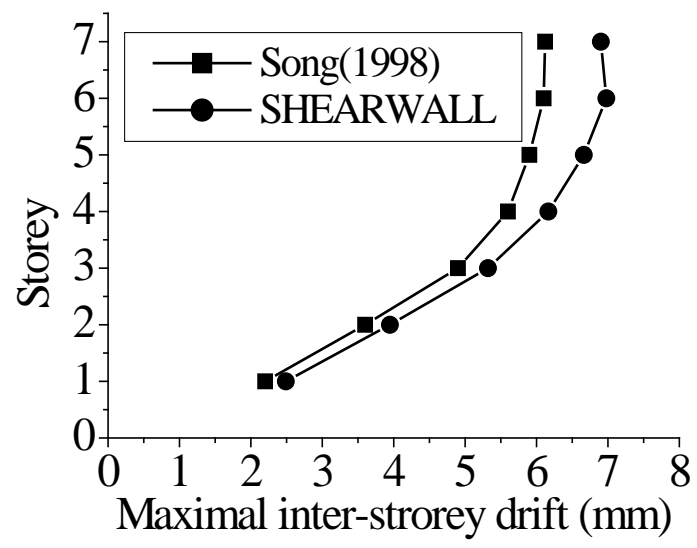

(b)

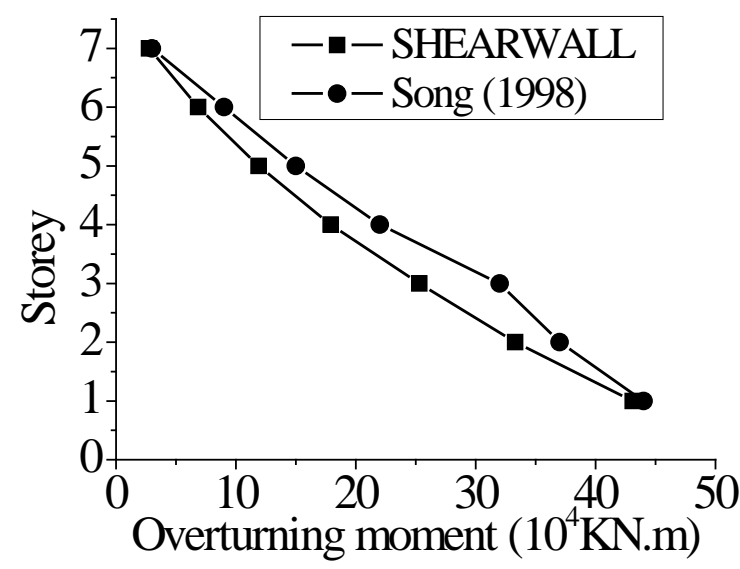

(d)

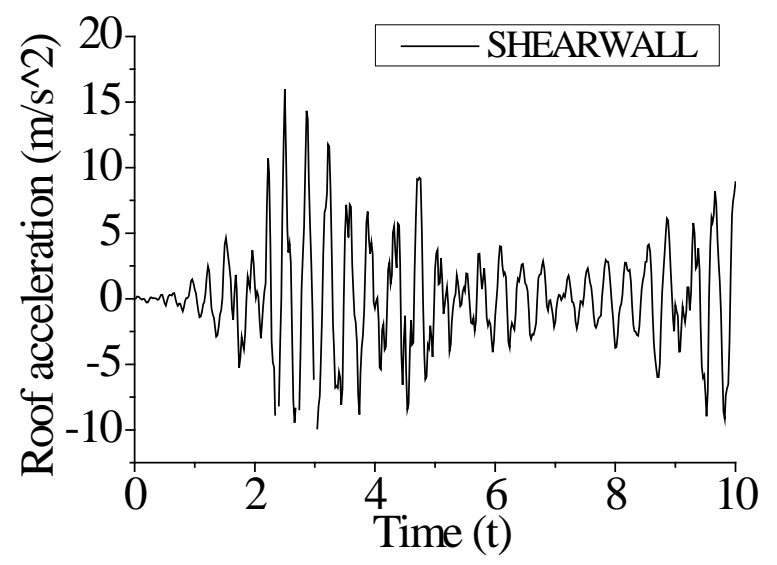

(f)

Fig. 12 Time-history analyse results of Example 3: (a) maximal storey drift; (b) maximal inter-storey drift; (c) maximal inter-storey shear force; (d) maximal overturning moment; (e) top drift time-history; and (f) roof acceleration time-history 

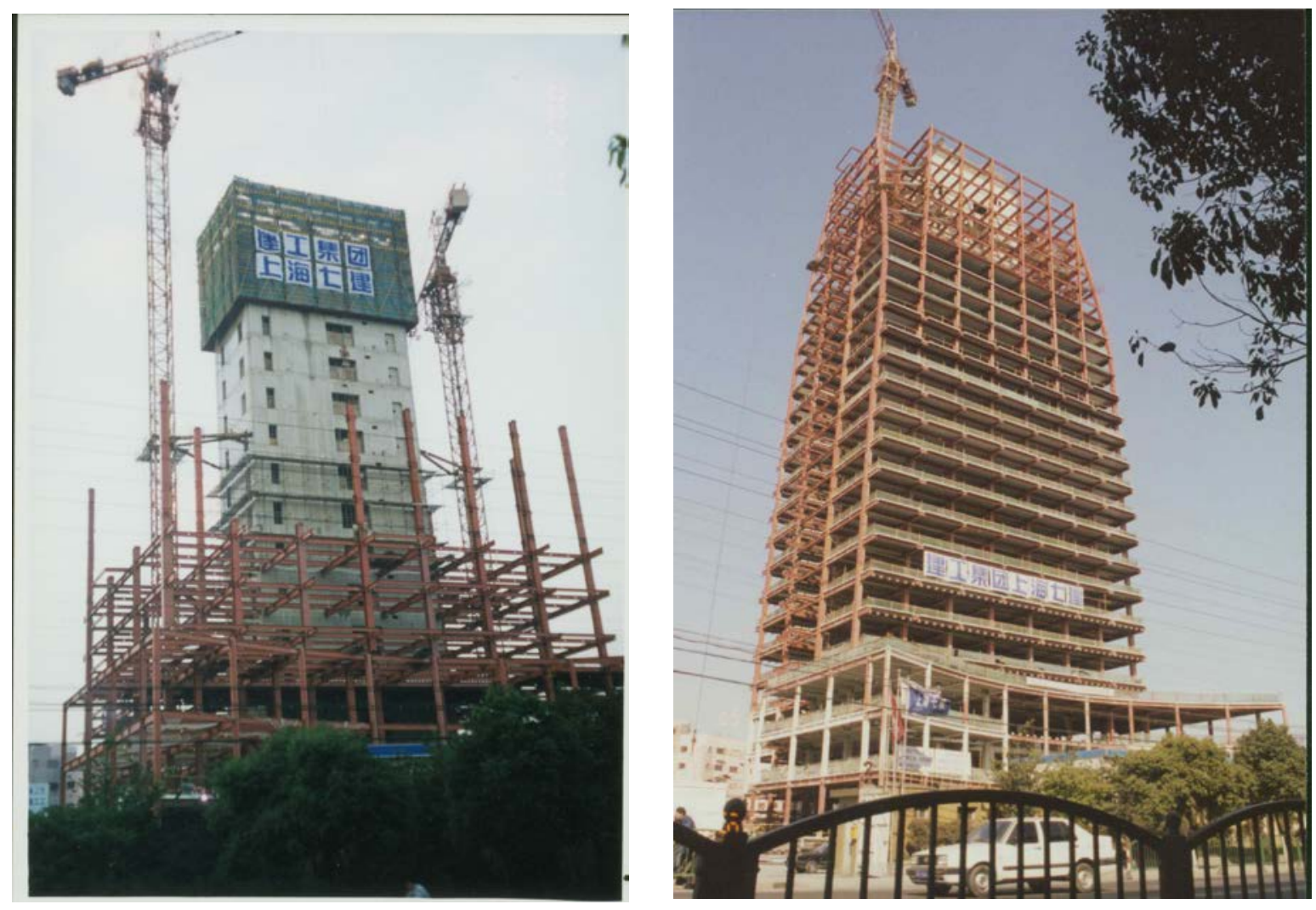

Fig. 13 The prototype building under construction (a) concrete tube nearly completed; and (b) composite structure nearly completed 


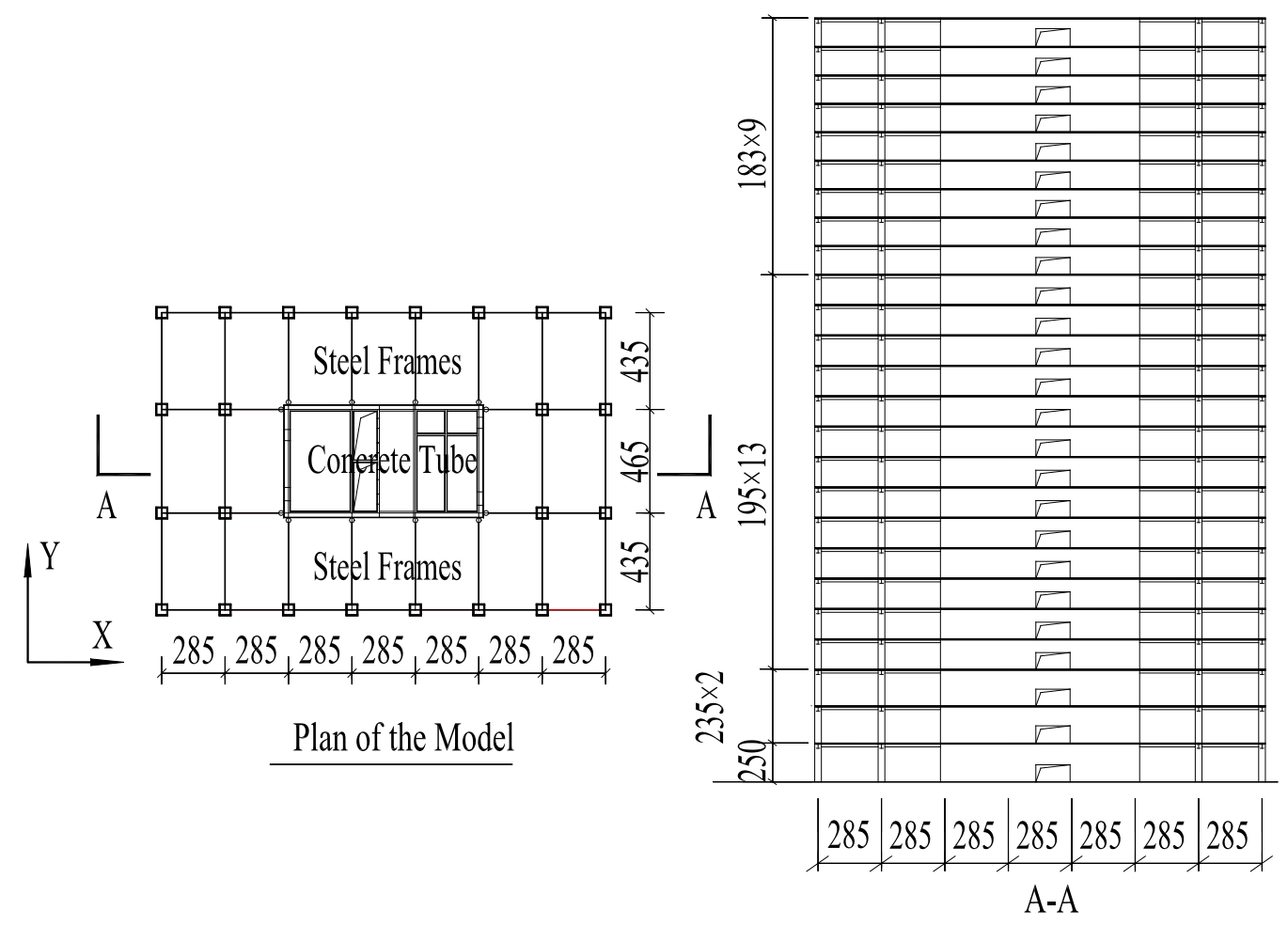

Fig.14 The model structure: (a) typical floor plan; and (b) the elevation (section A-A) (all dimensions are in $\mathrm{mm}$ ) 


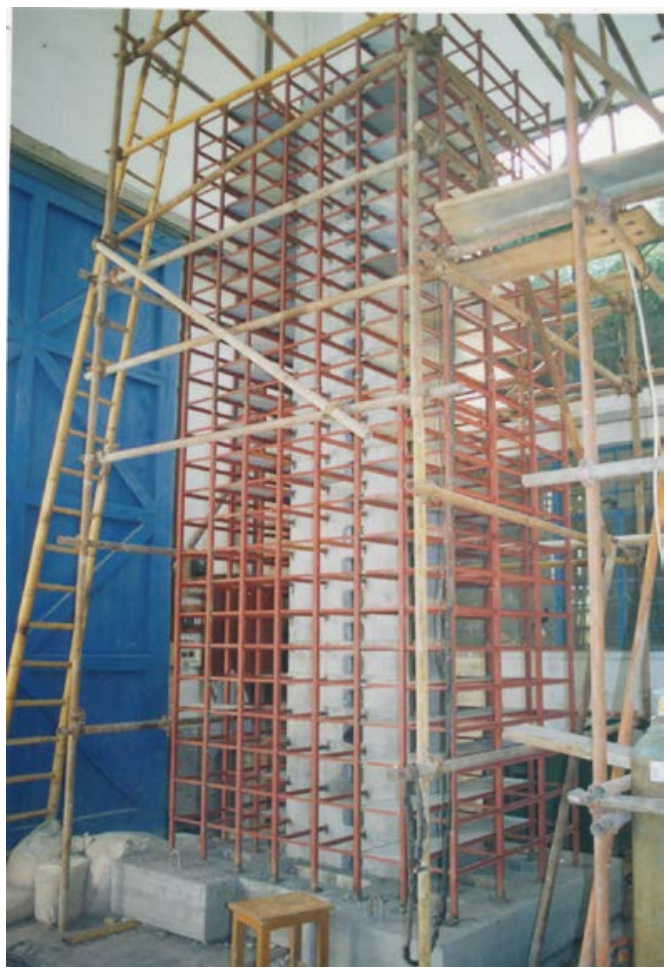

Fig. 15 The composite model structure: (a) SF and CT fixed on the base (concrete slabs yet cast); and (b) the completed model structure installed on the shaking table with additional mass 